\title{
APROPIACIÓN DE ESTRATEGIAS PEDAGÓGICAS Y DIDÁCTICAS EN LOS PROCESOS DE ENSEÑANZA- APRENDIZAJE EN LOS PROFESORES QUE INCORPORAN LAS TIC EN EL PROGRAMA TECNOLOGÍA INFORMÁTICA, UNIMINUTO, CENTRO REGIONAL SOACHA -CRS-1
}

\author{
APPROPRIATION OF PEDAGOGICAL AND DIDACTIC STRATEGIES \\ IN THE TEACHING-LEARNING PROCESSES IN TEACHERS WHO \\ INCORPORATE THE ICT IN THE COMPUTER TECHNOLOGY PROGRAM \\ AT UNIMINUTO, CENTRO REGIONAL SOACHA -CRS- \\ APROPRIACÃO DAS ESTRATÉGIAS PEDAGÓGICAS E DIDÁTICAS NOS PROCESSOS DE \\ ENSINO- APRENDIZAGEM NOS PROFESSORES QUE INCORPORAM AS TIC NO PROGRAMA \\ TECNOLOGIA INFORMÁTICA, UNIMINUTO, CENTRO REGIONAL SOACHA -CRS- \\ Leydy Viviana Colmenares Montero²
}

Fecha de recibido: Febrero 05 de 2017 | Fecha de aprobado: Abril 22 de 2017

\section{Resumen}

La investigación describe cómo los docentes del programa Tecnología Informática de la UNIMINUTO -CRS-, apropian las estrategias pedagógicas y didácticas en los procesos de enseñanza-aprendizaje, utilizando como medio las TIC. Se trabajó desde el método de investigación-acción, con un enfoque cualitativo, dirigido a una muestra de seis docentes. Los resultados sugieren que los profesores del programa incorporan y apropian las estrategias basados en su formación académica y experiencia, e identifican fortalezas sobre la interacción de los estudiantes con las estrategias propuestas y debilidades del proceso respecto a las limitaciones de infraestructura tecnológica.

Palabras clave: aprendizaje, apropiación, enseñanza, estrategia, tecnologías de la información y comunicación -TIC-.

1 Artículo de investigación.

2 Ingeniera en Redes de Computadores. Maestra en Educación. UNIMINUTO, Facultad de Ingeniería. Bogotá, Colombia. Correo electrónico: Icolmenares@uniminuto.edu. 


\section{Abstract}

This research describes how teachers of the IT Technology program at UNIMINUTO -CRS-, appropriate pedagogical and didactic strategies in the teaching-learning processes, using ICT as a pedagogical means. We worked with a research-action method, with a qualitative approach directed to a sample of six teachers. The results suggest that teachers incorporate and appropriate strategies based on their academic background and experience, and identify strengths regarding students' interactions with the strategies proposed, as well as weaknesses of the process related to technological infrastructure constraints.

Key Words: learning, appropriation, teaching, strategy, information and communication technologies -ICT-.

\section{Resumo}

A investigação descreve como os docentes do programe Tecnologia Informática da UNIMINUTO -CRS-, apropriam as estratégias pedagógicas e didáticas nos processos de ensino-aprendizagem, utilizando como médio as Tic. Trabalhou-se desde o método de investigação-ação, com um enfoque qualitativo, dirigido a uma mostra de seis docentes. Os resultados sugerem que os professores do programa incorporam e apropriam as estratégias baseados em sua formação acadêmica e experiência, e identificam fortalezas sobre a interação dos estudantes com as estratégias propostas e debilidades do processo com respeito às limitações de infraestrutura tecnológica.

Palavras-chave: aprendizagem, apropriação, ensino, estratégia, Tecnologias da Informação e Comunicação -TIC-. 


\section{INTRODUCCIÓN}

Con la evolución tecnológica, la sociedad actual demanda al sector educativo la innovación en los procesos de enseñanza-aprendizaje y la implementación de estrategias pedagógicas y didácticas mediadas por herramientas tecnológicas que permitan al profesor aplicar un conjunto de procedimientos organizados que concentren la atención en el estudiante como eje de su proceso de aprendizaje. Prueba de esto es que UNIMINUTO adelanta un proceso de autoevaluación y acreditación institucional.

Entre los factores más importantes referenciados por el Ministerio de Educación Nacional -MEN- (2010) y el Consejo Nacional de Acreditación -CNA- (2013) se encuentran la apreciación y percepción de estrategias pedagógicas, la organización de las actividades por medio de las TIC y los profesores. Estas atañen a la formación y experiencia acorde al programa, dentro de las cuales las instituciones deben propender por programas de desarrollo profesoral adecuados a sus necesidades específicas. Una de las mayores preocupaciones que se presenta reside en los procesos de aprendizaje y la incorporación de estrategias mediadas por las TIC y la efectividad de las mismas. A partir de esta necesidad es importante intervenir y realizar una investigación para determinar cómo ocurre la apropiación de estrategias pedagógicas y didácticas en los procesos de enseñanza-aprendizaje en los profesores que incorporan las TIC en el programa Tecnología Informática, UNIMINUTO, -CRS-, un contexto en el que los docentes son profesionales del área específica o disciplinar y, aunque cuentan con una amplia experiencia en el campo profesional, tienen poca o ninguna formación en docencia universitaria.

El objetivo de la investigación consiste en revisar las prácticas docentes, analizando las estrategias, medios y recursos que intervienen para contribuir al mejoramiento de los procesos de enseñanza-aprendizaje a través del reconocimiento de las fortalezas y debilidades, y, de ese modo, generar recomendaciones de implicación práctica para la institución.

\section{MARCO TEÓRICO}

Para formular el problema, analizar los datos y resultados obtenidos fue necesario llevar a cabo una revisión de la literatura para delimitar la pertinencia y el alcance de la investigación educativa. A continuación, se presentan diferentes fundamentos teóricos e investigaciones relacionadas que dan soporte a la investigación.
La apropiación educativa surge como la relación de actividades mediadas por herramientas tecnológicas que posibilitan generar estructura en la interpretación y construcción del aprendizaje (Colás, Rodríguez, \& Jiménez, 2005). Por lo que los maestros aprenden el uso de las herramientas informáticas y modifican su práctica educativa al desarrollar sus propias estrategias pedagógicas y didácticas; así, la apropiación dependerá de su utilidad y los beneficios percibidos por el profesor.

En cuanto a los niveles que un usuario puede tener ante la apropiación de una tecnología, Hooper y Rieber (1995) señalan los siguientes: familiarización, utilización, integración y reorientación. Es en la fase final cuando el ambiente de aprendizaje se apoya en las tecnologías y es utilizado como herramienta para la construcción del conocimiento. En correspondencia a los niveles descritos, es relevante señalar que, dentro de la historia educativa de Colombia de inicios del siglo xxı, la educación pública y privada comenzó el proceso de utilización e integración de nuevas tecnologías, que perduró como el medio por el cual los docentes dictaban sus clases, apoyados en medios para transmitir conocimientos como el proyector de filminas, acetatos y video beam (Parra, 2012); situación que en la actualidad es percibida por los docentes mediante diferentes experiencias que hacen evidente y visible la necesidad de indagar cuál es el grado de apropiación de estrategias mediadas por las TIC en los procesos de enseñanza.

Una aproximación a la realidad consiste en que la enseñanza surge del intercambio entre la actuación del profesor y el alumno en un ambiente de aprendizaje con algunos medios y estrategias (Meneses, 2007). La enseñanza está presente en cada una de las actividades que lleven a los estudiantes a aprender y a ejercitar la aplicación de habilidades y destrezas. Estudios han revelado que la enseñanza implica que los estudiantes aprenden no sólo de ejercicios o contenidos, pues estos tienen una estructura cognitiva que les permite explicar el conocimiento a través de sus propias palabras (Bereiter \& Scardamalia, 1987; Glaser, 1984).

De acuerdo a Heredia y Sánchez (2012), el aprendizaje es un cambio permanente en la conducta como resultado de la experiencia, por tanto, los maestros deben instruir o enseñar la ruta del aprendizaje por medio de las habilidades y la utilización adecuada de las estrategias pedagógicas y didácticas apoyadas en el uso eficiente de las TIC, de manera que 
propendan por la construcción del conocimiento personal y grupal.

El proceso de enseñanza-aprendizaje cuenta con unos elementos, expuestos por Meneses (2007), entre los cuales se encuentran el docente, el estudiante, el contenido, las estrategias, los medios, el contexto y los ambientes, sin olvidar la visión curricular, que se enfoca en los pasos o acciones para conseguir las metas y objetivos.

Las estrategias pedagógicas y didácticas son las acciones, estructuras o pasos creados y planificados que el maestro realiza para desarrollar diferentes acciones desde el proceso de enseñanza-aprendizaje, con el propósito de facilitar la formación y cumplir así con la meta de aprendizaje. De acuerdo al Instituto Tecnológico de Monterrey -ITESM- (2010), tales estrategias resultan como el producto de un conjunto de procedimientos apoyados en técnicas de enseñanza, actividades que integran diferentes contenidos y recursos que tienen como finalidad alcanzar el aprendizaje. Actualmente, se promueve un modelo educativo que se centra en el alumno, por esta razón el profesor diseña las actividades de aprendizaje, enseña a aprender y evalúa; en tanto, el alumno realiza actividades, construye su propio aprendizaje y se autoevalúa.

Tal y como lo describe Beltrán (2002), «las estrategias sirven para mejorar la calidad del rendimiento de los alumnos, pero las estrategias, lógicamente, deben estar apoyadas en alguna concepción del aprendizaje» (p. 1). Adicional a ello, atendiendo lo relacionado por Caji (1992), es importante someter las estrategias a diseños experimentales e investigativos, por lo que los docentes deben constituirlas de acuerdo a fases de diseño, planeación y la evaluación. Para la construcción de las estrategias, Gargallo (2006) propone diferentes elementos y características entre las que se encuentran la independencia, supervisión, autodirección y evaluación, de ese modo, se permite realizar modificaciones según las necesidades, medios y contextos a ser aplicados.

En relación con los medios y según Escontrela y Stojanovic (2004) y Moya (2009), las TIC se han convertido en el elemento clave de los diferentes sistemas educativos. El objetivo actual es el logro de mejores aprendizajes para potenciar la curiosidad e interés de los estudiantes mediante diferentes estrategias que utilicen estas herramientas como medios, y en el que la función del docente será la de un orientador. Sin embargo, es menester considerar los dominios de desarrollo propuestos por Salinas (2008) -que desarrollan las posibilidades educativas-, entre los cuales se encuentran la tecnología física, protocolos de software, los programas de aplicación, el diseño educativo y el diseño de aprendizaje.

En este punto es preciso mencionar componentes básicos, tipos y características de las estrategias didácticas y la importancia de los elementos que intervienen en la estrategia para lograr aprendizajes significativos, tales como: nombre de la estrategia, contexto, duración, objetivos, competencias, sustentación teórica, contenidos, secuencia didáctica, recursos y estrategias de evaluación.

Sobre las estrategias y técnicas didácticas, Bustos (2005), ITESM (2010) y Pimienta (2012) proponen su organización de acuerdo a su finalidad, para lo cual hay que indagar acerca de los conocimientos y la organización de información, promover la comprensión, sobre los cuales se deriva la estrategia o técnica: preguntas, cuadros comparativos, exposición, resumen, foros, aprendizaje basado en proyectos, aprendizaje basado en las TIC, aprendizaje colaborativo, aprendizaje autónomo, entre otros.

En cuanto a los criterios para la selección de estrategias y técnicas, el maestro debe identificar características para tomar decisiones. De acuerdo a ITESM (2010), Rivero, Gómez y Abrego (2013), éstas conciernen a la validez, variedad, relevancia, claridad, adecuación, conocimiento e inserción. Bajo estos factores, es fundamental que el maestro reflexione sobre la programación de la actividad, los roles y papeles de los estudiantes, que conlleven a la finalidad educativa.

En términos de la reflexión educativa, es relevante considerar experiencias que permitan evaluar los grados de apropiación de estrategias pedagógicas mediadas por las TIC en Colombia. El estudio desarrollado por Castellano y Arboleda (2013) presenta la evaluación de las estrategias didácticas y TIC, con el objetivo de mejorar las condiciones y prácticas de enseñanza para el desarrollo de competencias implementadas en las instituciones educativas de Medellín, Colombia.

El tipo de investigación aquí realizada es mixta, pues incorpora elementos cualitativos y cuantitativos. Las unidades de análisis son estudiantes en formación profesional ciclo Tecnológico y docentes de las áreas de Tecnología Informática. Entre los instrumentos utilizados se encuentran la entrevista semiestructurada, el análisis de documentos y observación aplicado a los docentes, y la escala de Likert para evaluar 
la percepción de los estudiantes sobre las estrategias y medios utilizados por los docentes.

Los resultados señalan que para los docentes las estrategias didácticas tienen correlación con los procesos de apropiación de conocimiento por los estudiantes y con las TIC, como elementos que inciden en los ambientes de aprendizaje y generan que los procesos asociados al aprendizaje se puedan realizar. En últimas, el desafío para los docentes en Colombia consiste en la incorporación de estrategias basadas en TIC como herramientas mediadoras en las prácticas de enseñanza.

\section{METODOLOGÍA}

El paradigma del estudio es teórico-crítico, el cual sustenta al método de investigación- acción; según Valenzuela y Flores (2012), este método comparte características con el cualitativo, cuyo objeto es un proceso por el que los profesores proponen cambiar algo o mejorar su propia práctica. Dado lo anterior, se justifica la elección del método, pues se plantea una interrogante frente al ejercicio docente que va de la mano con una acción de mejora.

La investigación se desarrolló en cinco fases ejecutadas a través de ciclos que incorporaron observación, reflexión y planificación, razón por la cual la investigación implicó:

Un plan de acción: planteamiento e identificación del problema de investigación sobre una situación de interés que puede ser manejada, mejorada y que implique la enseñanza y el aprendizaje (Blasco \& Pérez, 2007).

El diagnóstico, descripción y explicación de la situación: diagnóstico de la situación y revisión documental. Para este, se definieron los objetivos y propósito de la investigación, continuando con los supuestos de investigación y soportándola con base en el marco teórico, y consistió en el estudio de las situaciones o investigaciones similares que aportaran al caso.

La acción: el desarrollo de esta fase radicó en la acción o plan a ejecutar para resolver los supuestos, por lo que fue necesario organizar y secuenciar los pasos a seguir.

La observación o supervisión de la acción y resultados: esta se centró en la observación de la acción, en la que se comprobó el desarrollo de la misma. Permitió relacionar elementos para sostener afirmaciones sujetas a los cambios ocasionados como consecuencias de la acción. Esta fase fue producida gracias a la recolección de información a través de los instrumentos que permitieron la captura de datos: entrevista, observación y análisis de documentos.

La reflexión o análisis de los datos, conclusiones y recomendaciones: esta fase cierra el ciclo y genera el informe o replanteamiento. El informe de investigación, una vez concluidos los ciclos, hace referencia al documento que muestra los resultados del proceso de investigación. El informe dio cuenta de los siguientes aspectos: ¿cómo evoluciona la idea?, ¿cómo evoluciona la comprensión del problema?, decisiones tomadas sobre la comprensión del problema, efectos o resultados de las acciones, técnicas utilizadas para recoger la información, problemas encontrados, problemas éticos identificados.

\section{Participantes y selección de la muestra}

Para la selección de los participantes se tuvieron en cuenta factores como la conveniencia de tiempo, la localización o disposición de lugares e informantes (Valenzuela \& Flores, 2012); se valoró que los profesores participantes estuvieran vinculados a la Universidad, pues esto facilitaba la obtención de información.

Un criterio fundamental fue la selección basada en áreas del programa - programación, redes de computadores, investigación y sistemas de información-, debido a que los instructores tienen encuentros presenciales y virtuales en laboratorios de computadores, acordes al objetivo de investigación. En conclusión, fue seleccionada una muestra representativa de seis docentes, que orientan asignaturas de primer a sexto semestre en el programa de Tecnología Informática.

\section{Instrumentos de recolección de datos}

Los instrumentos de recolección de datos fueron: análisis de documentos, observación de clase y entrevista semiestructurada, los cuales incluyeron una validación dada por tres jueces expertos afines al área de investigación, $y$, adicionalmente, una prueba piloto para garantizar la pertinencia de los mismos. El objetivo fue recolectar información que pudiera ser organizada y codificada, y así encontrar categorías y triangular datos que dieran respuesta a las preguntas y objetivos de la investigación; además de verificar 
hallazgos en contraposición con otros autores que den validez al estudio (Giroux \& Tremblay, 2004).

\section{Procedimiento en la aplicación de instrumentos}

Para la aplicación de los instrumentos se estableció un diálogo con los profesores, explicando la intención y los objetivos de la investigación. En este proceso fue relevante haber establecido un cronograma o plan de trabajo en conjunto con los participantes, con fechas, horas y lugares para su aplicación, de tal forma que éste ocurriera de manera transparente y no obstruyera o distrajera los procesos académicos.

Los instrumentos fueron aplicados, primero, con la observación, acto seguido se aplicó la revisión documental y, por último, la entrevista semiestructurada.

\section{Análisis de datos}

El análisis de datos consistió en los siguientes pasos: transcripción de datos, lectura reflexiva, codificación, y la creación de la matriz de análisis -apéndice D-, en la que emergen las categorías que reflejaron la temática particular del estudio. Los nombres provinieron del investigador, los participantes y la literatura, asimismo reflejan el tema de estudio, responden a las preguntas y objetivos de investigación.
El proceso de validación se llevó a cabo a través de la triangulación de los datos, realizada mediante el cuadro de triple entrada -apéndice E-. Esta técnica permite dar credibilidad y validez a los resultados del estudio, pues se contrastan diferentes fuentes de datos proporcionados por las herramientas de recolección de datos, y así se asegura la validez de los datos a la luz de las teorías de diferentes autores que fundamentaron el estudio.

\section{RESULTADOS}

Los resultados de la investigación se ilustran en la figura 1. Allí se visualizan las categorías que fueron relevantes para el estudio. Cada una reflejó el análisis de los datos más relevantes, es decir, la evidencia obtenida a través de la aplicación de los instrumentos, los cuales dan respuesta a la pregunta macro de la investigación teniendo como eje el objetivo general del estudio.

Antes de la figura, se expone a través de cada una de las categorías la discusión entre los resultados de acuerdo con los criterios establecidos en la metodología e interpretados con base en el marco teórico. Se extrajeron los hallazgos más importantes del estudio realizado, garantizando la confiabilidad y validez que den respuesta a la pregunta y objetivo de investigación.

Figura 1. Categorías de la investigación

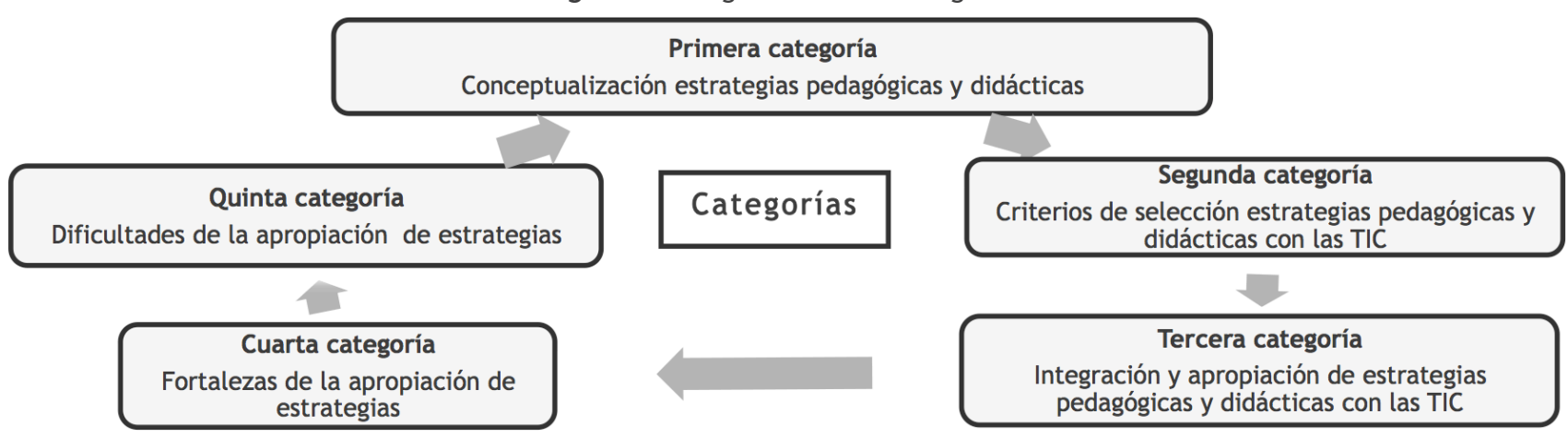

Fuente: elaboración propia.

\section{Conceptualización de las estrategias pedagógicas y didácticas}

La categoría presenta el elemento fundamental ante el proceso de apropiación, el conocimiento. Los docentes conocen las estrategias y las expresan, a partir de su definición y ejemplos, en la transcripción de las entrevistas semiestructuradas aplicadas -apéndice $\mathrm{C}$-. Los docentes conocen el significado de las estrategias, las describen como «el conjunto de procedimientos, métodos y técnicas que permiten que nosotros como docentes apoyemos el 
proceso de enseñanza-aprendizaje de los estudiantes» (US-E-02:27-29) ${ }^{3}$, relacionando un tiempo de discernimiento y demostrándolo al exhibir diferentes estrategias (Bustos, 2005; ITESM, 2010; Pimienta, 2012), consideradas como componentes básicos ante el proceso de apropiación.

\section{Criterios de selección estrategias pedagógicas y didácticas con las TIC}

Tales criterios están compuestos por tres subcategorías: obtención, criterios o pautas de selección y documentación de las estrategias, y presentan los aspectos fundamentales a la hora de seleccionar una estrategia. En la transcripción de las entrevistas semiestructuradas aplicadas a los docentes -apéndice $\mathrm{C}-$, los profesores relacionan criterios de selección como la experiencia profesional y académica, conocimiento familiar, búsquedas en internet y apoyo de los compañeros: «el conocimiento viene de la parte familiar [...] el internet, los libros [...] el apoyo de algunos compañeros» (US-E-2: 56-61); los aspectos anteriores son considerados como criterios y fuentes apropiadas de acuerdo a ITESM (2010), Rivero, Gómez y Abrego (2013), sin embargo, algunos docentes señalan que es menester que la institución educativa propenda por fuentes de información fiables, materiales didácticos y diferentes recursos accesibles para su consulta.

\section{Integración y apropiación de estrategias} pedagógicas y didacticas con las TIC

Conformada por tres subcategorías: apropiación, estrategias utilizadas y aplicación. Las categorías presentan las estrategias y el procedimiento empleado, para ello es conveniente observar las tablas 1 y 2.

Tabla 1. Tipo de estrategias utilizadas por docentes

\begin{tabular}{|c|c|c|c|c|c|c|c|}
\hline & \multicolumn{6}{|c|}{ Docente } \\
\hline & & 1 & 2 & 3 & 4 & 5 & 6 \\
\hline \multirow{4}{*}{ 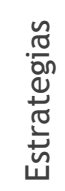 } & Aprendizaje basado en proyectos & & & & & & \\
\hline & Preguntas & & & & & & \\
\hline & Explicación instruccional & & & & & & \\
\hline & Aprendizaje basado en las TIC & & & & & & \\
\hline
\end{tabular}

Fuente: elaboración propia.

3 Codificación otorgada por los investigadores a cada instrumento de recolección de datos.
Tabla 2. Estrategias TIC

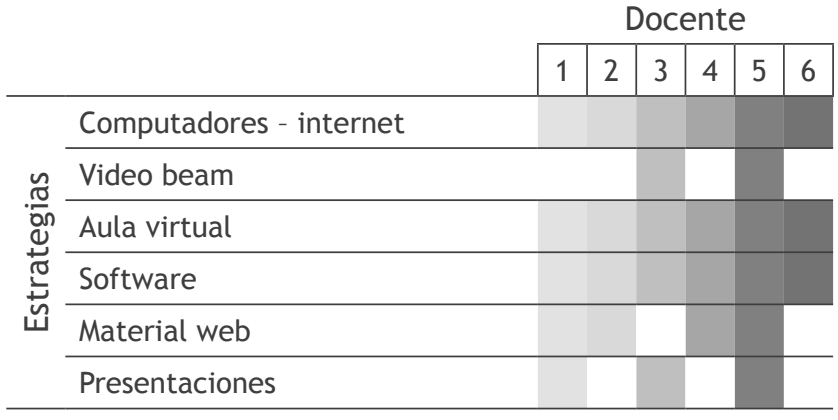

Fuente: elaboración propia.

Como resultado de la categoría, los docentes incorporan, adaptan, modifican y utilizan procedimientos de aplicación de estrategias pedagógicas y didácticas mediadas por las TIC (Bustos, 2005; ITESM, 2010; Pimienta, 2012), motivo por el cual se concibe la apropiación y se señala que una muestra tiene dificultades frente al proceso.

\section{Fortalezas de la apropiación de las estrategias}

Los docentes perciben múltiples ventajas y fortalezas en la apropiación, que van desde la concepción de la estrategia hasta la mediación con las TIC y cómo se promueven aprendizajes significativos en los estudiantes (Lombillo, Valera, \& Rodríguez, 2011). El panorama anterior está soportado por la transcripción de los formatos de observación -apéndice B- allí se aprecia que los profesores vinculan la facilidad de la apropiación en la incorporación de las TIC con las estrategias pedagógicas y didácticas, basados en su formación y experiencia en el área: «facilidad en la obtención, selección e integración de las TIC por experiencia docente y el conocimiento de las herramientas web [...] depende también del grupo, [...] entra el análisis del contenido, contexto y población» (US-0-3: 110-122).

\section{Dificultades de la apropiación de las estrategias}

La mayor dificultad descrita por los docentes es el problema de conectividad a internet para el acceso al aula virtual y la ausencia del software requerido para sus clases, problema que emerge de la transcripción de los formatos de observación -apéndice B- y que consiste en la falta de conexión a internet para el acceso al aula virtual de Moodle y la ausencia del software requerido para el adecuado 
desarrollo de las clases, por lo que los actores del proceso académico no cuentan con los medios y herramientas idóneos de trabajo: «en el desarrollo de la clase se hacen evidentes problemas de conexión a internet» (US-0-1-: 15-18).

Bajo esta circunstancia, las instituciones de educación superior deberán garantizar los recursos. Los profesores, a su vez, han de tener en cuenta en el diseño de las estrategias la región y el contexto, para propiciar la creación de espacios académicos agradables, dinámicos e interesantes que motiven la construcción del aprendizaje.

\section{DISCUSIÓN Y CONCLUSIÓN}

Sobre la pregunta principal de la investigación: ¿cómo ocurre la apropiación?

La investigación permitió establecer que los docentes incorporan y apropian las estrategias pedagógicas y didácticas mediadas por las TIC, lo cual se expresa a partir de la definición de los conceptos básicos o ejemplos expuestos en los instrumentos de recolección, relacionando un tiempo de discernimiento y demostrándolo al exhibir los criterios o pautas de selección, aplicando diferentes tipos de estrategias y procedimientos, e identificando plenamente las diferentes fortalezas y debilidades del proceso. Por consiguiente, se concluye que el objetivo fue cumplido satisfactoriamente, dado que la investigación presenta los resultados que emergen de cada una de las categorías, considerados como elementos básicos ante el proceso de apropiación, que responden a las preguntas y los objetivos específicos descritos a continuación.

\section{Criterios de selección}

Entre las fuentes consultadas para la selección de las estrategias, se encuentra la experiencia profesional y académica, el conocimiento familiar, búsquedas en internet y apoyo de los compañeros. Los criterios de selección refieren un rango en el que se relaciona el conocimiento del contenido, la experiencia, validez, variedad, adecuación, relevancia, claridad, conocimiento y dominio de procedimientos.

Según la documentación suministrada por la institución para consultas sobre estrategias, los docentes afirman que la biblioteca de la universidad cuenta con diversos recursos físicos y virtuales, pero no han profundizado sobre las estrategias.

\section{Estrategias utilizadas y procedimientos}

Entre las estrategias pedagógicas y didácticas más utilizadas están el aprendizaje basado en proyectos, preguntas, explicación instruccional y aprendizaje basado en las TIC, las cuales constituyen el medio por el que finalmente el estudiante alcanza el logro del aprendizaje. Respecto al procedimiento de apropiación, los docentes indican que las clases y estrategias son un ejercicio programado previamente, razón por la cual relacionan diversos elementos de la planeación tales como: nombre de la actividad, tipo de estrategia, clasificación, alcance, objetivos, contenido, material, secuencia didáctica, retroalimentación, recursos y medios, estrategias de evaluación.

\section{Fortalezas y dificultades}

Frente a las fortalezas y ventajas, los participantes señalan la facilidad de incorporación de las TIC en las estrategias, de acuerdo a su formación académica y experiencia. En cuanto a la interacción de los estudiantes, lo describen como un proceso fácil por la variedad de estrategias, lo que conlleva a pensamientos creativos y críticos. No obstante, los docentes proponen una capacitación para fomentar el uso por parte de la institución educativa.

Las dificultades del proceso involucran limitaciones respecto a la infraestructura tecnológica, el problema de conexión a internet y la ausencia del software requerido para las clases; adicionalmente, los docentes no cuentan con tiempo suficiente para la preparación de las clases y una muestra describe el no conocimiento de las estrategias y del cómo seleccionarlas acorde con el contexto, tema y dinámica académica.

\section{RECOMENDACIONES}

Realizar una capacitación sobre estrategias pedagógicas y didácticas mediadas por las TIC, dirigidas a los docentes del programa Tecnología Informática, que envuelvan las siguientes fases:

- Sensibilización sobre la importancia e incidencia en los procesos enseñanza- aprendizaje. 
- Explicación detallada afín al área tecnológica e ingenieril y exposición de los documentos y recursos físicos de la institución.

- Taller de tipos y clasificación de estrategias, y cómo integrarlas con las TIC.

- Exposición de la bitácora de aprendizaje a través del portafolio digital.

La recomendación final para la institución consiste en mejorar la disponibilidad de infraestructura tecnológica, pues la falta de ancho de banda, de acceso a los programas informáticos, representa una limitante considerable para el correcto desarrollo del programa académico.

En relación con la pregunta de investigación, que puede formularse hacia el futuro, es posible realizar una macroinvestigación dirigida a la apropiación de estrategias pedagógicas y didácticas de todos los docentes que orientan asignaturas afines al área ingenieril en los programas académicos de modalidad presencial de la Corporación Universitaria Minuto de Dios - UNIMINUTO.

\section{REFERENCIAS}

Beltrán, J. (2002). Procesos, estrategias y técnicas de aprendizaje. Madrid: Síntesis.

Bereiter, C., \& Scardamalia, M. (1987). The Psychology of Written Composition. Hillsdale, NJ: Lawrence Erlbaum Associates.

Blasco, J., \& Pérez, J. (2007). Metodologías de investigación en las ciencias de la actividad física y el deporte: Ampliando horizontes. Cottolengo: Editorial Club Universitario.

Bustos, A. (2005). Estrategias didácticas para el uso de las TIC's en la docencia universitaria presencial. Barcelona, Valparaíso: Pontificia Universidad Católica de Valparaíso.

Cajide, J. (1992). La investigación cualitativa: tradiciones y perspectivas contemporáneas. Bordón, 44(4), 357-373.

Castellano, M., \& Arboleda, B. (2013). Relación estrategias didácticas y TIC en el marco de prácticas pedagógicas de los docentes de instituciones educativas en Medellín. Revista virtual Universidad Católica del Norte, (38), 56-79.

Colás, P., Rodríguez, M., \& Jiménez, R. (2005). Evaluación de e-learning. Indicadores de calidad desde el enfoque sociocultural. Teoría de la Educación. Educación y Cultura en la Sociedad de la Información, 6(2), 1-12.

Consejo Nacional de Acreditación [CNA], Colombia. (2013). Lineamientos para la acreditación de programas de pregrado. Recuperado de http://www.cna.gov.co/1741/channel.html

Escontrela, R., \& Stojanovic, L. (2004). La integración de las TIC en la educación: apuntes para un modelo pedagógico pertinente. Revista de pedagogía, 25(74).

Gargallo, B. (2006). Estrategias de aprendizaje, rendimiento y otras variables relevantes en estudiantes universitarios. Revista de psicología general y aplicada, 59(1-2), 109 -130.

Giroux, S., \& Tremblay, G. (2004). Metodología de las ciencias sociales. México: Fondo de Cultura Económica.

Glaser, R. (1984). Education and thinking: the role of knowledge. American Psychologist, 39.

Heredia, Y., \& Sánchez, A. (2012). Definición del aprendizaje. En Teorías del aprendizaje en el contexto educativo. México: Editorial Digital.

Hooper, S., \& Rieber, L. (1995). Teaching with Technology. En A. C. Ornstein (Ed.), Teaching: Theory into practice, (pp. 154-170). Needham, Massachusetts, EE.uu: Allyn and Bacon. Recuperado de http://www.nowhereroad. $\mathrm{com} / \mathrm{twt} /$

Instituto Tecnológico de Monterrey [ITESM]. (2010). Centro virtual de técnicas didácticas. Investigación e innovación educativa. Recuperado de http://sitios.itesm.mx/va/dide2/tecnicas_didacticas/quesontd.htm

Lombillo, I., Valera, O., \& Rodríguez, I. (2011). Estrategia metodológica para la integración de las TIC como medio de enseñanza en la didáctica universitaria. Revista Apertura, 3(2). 
Meneses, G. (2007). Ntic, interacción y aprendizaje en la universidad. [Disertación doctoral]. De la base de datos de Tesis doctorales en red. Recuperado de http://www.tdx.cat/bitstream/handle/10803/8929/Elprocesodeensenanza.pdf?sequence $=32$

Ministerio de Educación Nacional [MEN], Colombia. (2010). Decreto 1295 del 20 de abril de 2010. Recuperado de http://www.mineducacion.gov.co/1621/articles-229430_archivo_pdf_decreto1295.pdf

Moya, A. (2009). Las nuevas tecnologías en la educación. Innovación y experiencias educativas, (24).

Parra, A. (2012). Las TIC y la educación en Colombia durante la década del noventa: alianzas y reacomodaciones entre el campo de las políticas educativas, el campo académico y el campo empresarial. Revista Educación y Pedagogía, 24(62), 173-189.

Pimienta, J. (2012). Estrategias de enseñanza aprendizaje. Docencia universitaria basada en competencias. México: Pearson.

Rivero, I., Gómez, M., \& Abrego, R. (2013). Tecnologías educativas y estrategias didácticas: criterios de selección. Revista Educación y Tecnología, (3), 190-206.

Salinas, J. (2008). Innovación educativa y uso de las TIC. Andalucía: Universidad Internacional de Andalucía.

Valenzuela, J., \& Flores, M. (2012). Fundamentos de investigación educativa. México: Editorial Digital del Tecnológico de Monterrey. 


\section{APÉNDICE A. \\ TRANSCRIPCIÓN FORMATO ANÁLISIS DE DOCUMENTOS}

\section{Docente 3. Formato análisis de documentos}

\begin{tabular}{|c|c|c|c|c|c|c|c|}
\hline $\begin{array}{c}\text { TIPO DE } \\
\text { DOCUMENTO }\end{array}$ & $\begin{array}{l}\text { APÉNDICE } \\
\text { N. }{ }^{\circ}\end{array}$ & $\begin{array}{l}\text { AUDIENCIA } \\
\text { OBJETIVO }\end{array}$ & $\begin{array}{l}\text { NOMBRE DEL } \\
\text { DOCUMENTO O } \\
\text { RECURSO }\end{array}$ & $\begin{array}{l}\text { PROCEDENCIA } \\
\text { ORIGEN }\end{array}$ & $\begin{array}{l}\text { OBJETIVO DEL } \\
\text { DOCUMENTO O } \\
\text { RECURSO }\end{array}$ & $\begin{array}{c}\text { TRABAJO } \\
\text { INDIVIDUAL } \\
\text { O GRUPAL }\end{array}$ & $\begin{array}{l}\text { TIEMPO } \\
\text { ESTIMADO }\end{array}$ \\
\hline \multicolumn{8}{|l|}{$\begin{array}{l}\text { Documentos } \\
\text { públicos }\end{array}$} \\
\hline \multicolumn{8}{|l|}{$\begin{array}{l}\text { Documentos } \\
\text { privados }\end{array}$} \\
\hline \multicolumn{8}{|l|}{$\begin{array}{l}\text { Documentos } \\
\text { populares }\end{array}$} \\
\hline $\begin{array}{l}\text { Materiales } \\
\text { audiovisuales } \\
\text { e informático }\end{array}$ & 1 & Estudiantes & $\begin{array}{l}\text { El guion } \\
\text { multimedial }\end{array}$ & Ana Obando & $\begin{array}{l}\text { Material de } \\
\text { presentación del } \\
\text { curso, requerimiento } \\
\text { o necesidad del guion } \\
\text { a desarrollar }\end{array}$ & $\begin{array}{l}\text { Individual } \\
\text { grupal }\end{array}$ & 8 días \\
\hline $\begin{array}{l}\text { Material } \\
\text { web páginas } \\
\text { web, ebook, } \\
\text { objetos } \\
\text { virtuales de } \\
\text { aprendizaje, } \\
\text { cursos } \\
\text { virtuales, } \\
\text { otros }\end{array}$ & 2 & Estudiantes & $\begin{array}{l}\text { Aula virtual } \\
\text { Mooodle }\end{array}$ & $\begin{array}{l}\text { http:// } \\
\text { pregrado. } \\
\text { uniminuto.edu }\end{array}$ & $\begin{array}{l}\text { Consiste en } \\
\text { herramientas de } \\
\text { las Tecnologías de } \\
\text { la Información y } \\
\text { Comunicación - } \\
\text { TIC- que facilitan } \\
\text { el proceso de } \\
\text { enseñanza, con } \\
\text { elementos como } \\
\text { repositorio de } \\
\text { documentos, talleres, } \\
\text { quiz, entre otros }\end{array}$ & $\begin{array}{l}\text { Individual } \\
\text { grupal }\end{array}$ & Semestre \\
\hline \multirow{3}{*}{$\begin{array}{l}\text { Herramientas } \\
\text { objetos } \\
\text { físicos, } \\
\text { implementos, } \\
\text { utensilios }\end{array}$} & 3 & Estudiantes & $\begin{array}{l}\text { Computador } \\
\text { con conexión a } \\
\text { internet }\end{array}$ & $\begin{array}{l}\text { UNIMINUTO, } \\
\text { Centro Regional } \\
\text { Soacha, } \\
\text { Laboratorio } 207\end{array}$ & $\begin{array}{l}\text { Por medio del } \\
\text { computador, } \\
\text { digitalizan } \\
\text { información, } \\
\text { visualizan documentos } \\
\text { y el aula virtual }\end{array}$ & $\begin{array}{l}\text { Individual } \\
\text { y grupal }\end{array}$ & Semestre \\
\hline & 4 & Estudiantes & $\begin{array}{l}\text { Software libre: } \\
\text { Php, eclipse, } \\
\text { block notas, } \\
\text { java script, } \\
\text { pdf. } \\
\text { Software } \\
\text { licenciado: } \\
\text { Excel, Cs3 }\end{array}$ & $\begin{array}{l}\text { UNIMINUTO, } \\
\text { Centro Regional } \\
\text { Soacha, } \\
\text { Laboratorio } 207\end{array}$ & $\begin{array}{l}\text { Generar aplicativos } \\
\text { apps para Android }\end{array}$ & $\begin{array}{l}\text { Individual } \\
\text { y grupal }\end{array}$ & Semestre \\
\hline & 5 & Estudiantes & Video beam & $\begin{array}{l}\text { UNIMINUTO, } \\
\text { Centro Regional } \\
\text { Soacha, } \\
\text { Laboratorio } 207\end{array}$ & $\begin{array}{l}\text { Proyectar la } \\
\text { presentación }\end{array}$ & $\begin{array}{l}\text { Individual } \\
\text { y grupal }\end{array}$ & 2 horas \\
\hline Código & \multicolumn{7}{|c|}{ US-D-03- -UNIMINUTO Soacha-Documentación-03- } \\
\hline
\end{tabular}




\section{APÉNDICE B \\ TRANSCRIPCIÓN FORMATO DE OBSERVACIÓN}

\section{Docente 4. Protocolo de observación}

\begin{tabular}{|c|c|c|}
\hline Ítem & Descripción & Observaciones adicionales \\
\hline Evento & $\begin{array}{l}\text { Laboratorio } 202 \text {. III corte. Semana } 15 . \\
\text { Asignatura: Metodología de investigación }\end{array}$ & \\
\hline Fecha & 5 de junio de 2014 & \\
\hline Duración -hora inicio - hora fin- & $8: 00$ am - 10:45 am & \\
\hline Participantes & 1 docente - 15 estudiantes & \\
\hline Lugar o contexto & $\begin{array}{l}\text { Laboratorio de } 15 \text { computadores con internet. } \\
\text { Promueve la interacción de la temática con las } \\
\text { Tecnologías de la Información y comunicación } \\
\text {-TIC- }\end{array}$ & $\begin{array}{l}\text { En el desarrollo de la clase se } \\
\text { hacen evidentes los problemas de } \\
\text { conexión a internet }\end{array}$ \\
\hline Temas principales & $\begin{array}{l}\text { Metodología de la investigación. Proyecto de } \\
\text { investigación }\end{array}$ & \\
\hline $\begin{array}{l}\text { Resumen de lo que sucede en la } \\
\text { clase/evento }\end{array}$ & $\begin{array}{l}\text { La profesora indica instrucciones para ingresar } \\
\text { al aula virtual, descargar unos archivos y aplicar } \\
\text { observaciones al proyecto, con la lista de chequeo } \\
\text { evalúa y retroalimenta }\end{array}$ & $\begin{array}{l}\text { La docente desarrolla una } \\
\text { explicación en el tablero }\end{array}$ \\
\hline Impresiones del investigador & $\begin{array}{l}\text { Buen dominio del tema, involucra a los estudiantes } \\
\text { en la construcción del aprendizaje } \\
\text { La docente apropia estrategias pedagógicas y } \\
\text { didácticas utilizando las TIC }\end{array}$ & $\begin{array}{l}\text { El contenido de la materia es } \\
\text { difícil para los estudiantes }\end{array}$ \\
\hline $\begin{array}{l}\text { Explicaciones o especulaciones } \\
\text { - hipótesis de lo que sucede en } \\
\text { el lugar frente a la aplicación } \\
\text { de estrategias pedagógicas y } \\
\text { didácticas en el aula- }\end{array}$ & $\begin{array}{l}\text { La docente utiliza estrategia de aprendizaje } \\
\text { orientada a proyectos } \\
\text { La profesora retroalimenta los avances de los } \\
\text { estudiantes } \\
\text { Se apoya en la explicación magistral para aclarar } \\
\text { puntos específicos al grupo en general }\end{array}$ & \\
\hline $\begin{array}{l}\text { Siguientes pasos en la recolección } \\
\text { de datos - qué se le debe solicitar } \\
\text { o preguntar al docente, en } \\
\text { situación de observación, de } \\
\text { manera adicional-- }\end{array}$ & $\begin{array}{l}\text { Material y recursos del aula virtual, registrar } \\
\text { documentos y aplicar entrevista }\end{array}$ & $\begin{array}{l}\text { Desde hace cuánto tiempo tienen } \\
\text { los recursos o materiales en el } \\
\text { aula virtual }\end{array}$ \\
\hline $\begin{array}{l}\text { Revisión } \\
\text { Actualización } \\
\text { Implicación de conclusiones }\end{array}$ & $\begin{array}{l}\text { La docente utiliza estrategias didácticas y } \\
\text { pedagógicas, se apoya integrando las TIC }\end{array}$ & \\
\hline Código & US-0-04- -UNIMINUTO Soacha-Observación-04- & \\
\hline
\end{tabular}




\begin{tabular}{|c|c|c|c|}
\hline CRITERIOS & ACTORES & ACCIONES A OBSERVAR & REGISTRO DE ACCIONES \\
\hline $\begin{array}{l}\text { Utilización y } \\
\text { aplicación de } \\
\text { estrategias } \\
\text { pedagógicas } \\
\text { y didácticas } \\
\text { con los } \\
\text { estudiantes }\end{array}$ & $\begin{array}{l}\text { Docente } \\
\text { estudiantes }\end{array}$ & $\begin{array}{l}\text { Nombre de la actividad } \\
\text { Tipo de estrategia } \\
\text { Clasificación estrategia - } \\
\text { autoaprendizaje, colaborativo, } \\
\text { interactivo- } \\
\text { Alcance - periodos cortos o largos- } \\
\text { Objetivos de su utilización } \\
\text { Contenido } \\
\text { Secuencia didáctica -cómo se apoya } \\
\text { en las tic- } \\
\text { Recursos y medios } \\
\text { Estrategias de evaluación } \\
\text { Interacción de los estudiantes con las } \\
\text { estrategias dentro del aula } \\
\text { Tiempo de interacción de los } \\
\text { estudiantes con las estrategias } \\
\text { Nivel de facilidad o dificultad de la } \\
\text { interacción con las estrategias de } \\
\text { parte de los estudiantes } \\
\text { Percepción del docente sobre el } \\
\text { nivel de facilidad o dificultad de la } \\
\text { interacción con las estrategias de } \\
\text { parte de los estudiantes }\end{array}$ & $\begin{array}{l}\text { Proyecto de investigación } \\
\text { Explicación magistral, preguntas abiertas, } \\
\text { aprendizaje orientado a proyectos } \\
\text { Colaborativo - autoaprendizaje - interactivo } \\
\text { Dos meses y medio } \\
\text { Construcción de un proyecto de investigación, } \\
\text { retroalimentación, verificación del aprendizaje } \\
\text { Metodología de investigación } \\
\text { La profesora indica instrucciones sobre el ingreso } \\
\text { al aula virtual y descarga unas observaciones para } \\
\text { completar la rúbrica de evaluación de la lista de } \\
\text { chequeo y cualificar el proyecto en el que llevan } \\
\text { trabajando dos meses y medio. Adicionalmente } \\
\text { realiza explicaciones en el tablero como } \\
\text { retroalimentación sobre los errores del proyecto } \\
\text { Respecto a los cronogramas entregados por los } \\
\text { grupos, cada uno presenta sus avances, realiza } \\
\text { preguntas abiertas, los estudiantes argumentan su } \\
\text { trabajo y les retroalimenta } \\
\text { Computadores, internet } \\
\text { Nota porcentual de la nota final del proyecto } \\
\text { Los estudiantes abren el aula y descargan el formato } \\
\text { de anteproyecto, trabajan sobre las observaciones, } \\
\text { la docente les retroalimenta su proyecto } \\
\text { Durante la clase y trabajo independiente } \\
\text { Dificultad: no por la estrategia, sino por el contenido } \\
\text { Dificultad: no por la estrategia, sino porque la } \\
\text { temática implica que los estudiantes piensen y } \\
\text { argumenten }\end{array}$ \\
\hline $\begin{array}{l}\text { Criterios de } \\
\text { selección } \\
\text { de las } \\
\text { estrategias }\end{array}$ & Docente & $\begin{array}{l}\text { Nombre de la actividad } \\
\text { Tipo de estrategia } \\
\text { Modo de obtención de las estrategias } \\
\text { pedagógicas y didácticas -fuentes- } \\
\text { Criterios de selección } \\
\text { Proceso o metodología empleada para } \\
\text { orientar las estrategias } \\
\text { Nivel de facilidad o dificultad en la } \\
\text { obtención de las estrategias } \\
\text { Nivel de facilidad o dificultad en la } \\
\text { selección de las estrategias } \\
\text { Nivel de facilidad o dificultad en la } \\
\text { utilización de las estrategias apoyado } \\
\text { en las TIC }\end{array}$ & $\begin{array}{l}\text { Proyecto de investigación } \\
\text { Explicación magistral, preguntas abiertas, } \\
\text { aprendizaje orientado a proyectos } \\
\text { De acuerdo a las necesidades del contenido y de } \\
\text { los estudiantes, basada en la experiencia, también } \\
\text { utiliza recursos web } \\
\text { Sobre el contenido, grupo y contexto } \\
\text { Comprensión del contenido, aplicación al contexto } \\
\text { Utiliza casos de la vida convencional, enfoca } \\
\text { el aprendizaje hacia el desarrollo de proyectos } \\
\text { interdisciplinares, retroalimenta el conocimiento } \\
\text { Facilidad por conocimiento previo y experiencia } \\
\text { previa a través de la web } \\
\text { Facilidad por conocimiento previo y experiencia } \\
\text { Facilidad por conocimiento previo y experiencia a fin } \\
\text { al área }\end{array}$ \\
\hline
\end{tabular}




\title{
APÉNDICE C. TRANSCRIPCIÓN ENTREVISTAS SEMIESTRUCTURADAS
}

\section{Docente 5. Entrevista semiestructurada}

\author{
Corporación Universitaria Minuto de Dios -UNIMINUTO-, Centro Regional Soacha \\ Guía para la orientación de la entrevista semiestructurada para identificar la \\ apropiación de estrategias pedagógicas y didácticas en el aula
}

Objetivo: indagar sobre la apropiación de estrategias pedagógicas y didácticas en las prácticas educativas de profesores adscritos al programa Tecnología Informática, UNIMINUTO, Centro Regional Soacha, Colombia.

\section{Características del entrevistado y contexto}

Universidad: Corporación Universitaria Minuto de Dios - UNIMINUTO- Centro Regional Soacha -CRS-

Nombre: 5 / Profesión: ingeniera en Redes de Computadores. / Otros estudios: especialización en seguridad de redes de computadores. / Tiempo de experiencia profesional y docente: 7 años profesional y docente.

Cursos a cargo: Sistemas Operativos, Informática Forense, Fundamentos de Seguridad en Redes, Seguridad en Redes. Niveles de los cursos: II, V, VI semestre, Tecnología Informática.

P. ¿Conoce el significado de «estrategias pedagógicas y didácticas»?

R. Las estrategias pedagógicas y didácticas son esas acciones que utiliza el docente para dar a conocer un tema a sus estudiantes.

P. ¿Desde cuándo conoce las estrategias pedagógicas y didácticas?

R. Hace más o menos unos 6 años.

P. ¿Ha utilizado las estrategias pedagógicas y didácticas en los procesos de enseñanza-aprendizaje?

R. Sí.

P. ¿Cuáles son las estrategias pedagógicas y didácticas más utilizadas y conocidas? ¿Por qué?

R. Pues me parece que una de las estrategias pedagógicas más utilizadas en mis clases es la esquematización de la información, a mi modo de ver uno tiene que hacer el análisis de la información para poder esquematizarla; de la misma manera, cuando uno la esquematiza la recuerda, la memoriza «sin querer», sin darse cuenta, son cuadros conceptuales, cuadros comparativos, mapas mentales.

P. ¿Cómo apoya e integra las estrategias pedagógicas y didácticas con las herramientas afines a las Tecnologías de la Información y Comunicación -TIC-?

R. Pues, por ejemplo, los mapas mentales, desde el aula virtual ellos tienen que cargar y descargar la información, entonces para cargar un mapa mental tienen que utilizar una herramienta tecnológica, tienen que mirar cómo se hace y tienen que mirar cuál es la que más se les facilita, entonces yo les doy varias opciones y ellos seleccionan la que más se les facilita y la que más les parezca, y sobre ella pueden subir la información.

P. ¿Cómo obtiene las estrategias pedagógicas y didácticas, es decir, a través de qué recursos: físicos -libros, internet- o humanos -asesoría o apoyo de expertos-, u otros?

R. Pues lo utilizo a partir de mi vivencia personal, de mi experiencia como profesora y como estudiante, digamos que a mí como estudiante se me dificultaba mucho hacer esos cuadros y sufría mucho cuando me ponían hacerlos, pero recuerdo los cuadros que hice, entonces una vez me pusieron a hacer un cuadro que era muy extenso pero en la actualidad logro recordar lo que hice en ese cuadro, a pesar de que fue muy extenso, logro recordar: los numerales, las terminologías y a qué hace referencia cada una de ellas.

P. ¿Cuáles son los criterios o pautas utilizadas para la selección de las estrategias pedagógicas y didácticas?

R. Pues los criterios como tal son el grupo al que se le va a aplicar la estrategia, el tema que se va a tratar en la sesión y el tiempo de la sesión.

P. ¿Considera que las siguientes características: conocimiento del contenido, experiencia, validez, comprensividad, variedad, adecuación, relevancia, claridad, adecuación, conocimiento y dominio de los procedimientos, influyen en la selección de las estrategias pedagógicas y didácticas? ¿Por qué?

R. Sí. Porque cuando yo conozco el tema sé qué estrategia me puede servir para cierto tema y qué estrategia no es la más pertinente, entonces, en algún tema específico muy teórico, si yo utilizo una estrategia como un resumen, por ejemplo, a los muchachos se les torna más monótono, entonces en ese tipo de temas yo utilizo algo que sea más dinámico o que ellos puedan utilizar otra metodología que les llame la atención para que se motiven y no se duerman en la clase.

P. ¿Con qué frecuencia utiliza las estrategias pedagógicas y didácticas: siempre, casi siempre, de vez en cuando...? ¿Por qué?

R. Digamos que casi siempre hay que buscar una estrategia para que los muchachos tengan alguna actividad o hagan alguna cosa en la clase, porque si yo les dicto todo el tiempo, entonces se torna monótono, aburrido, se cansan y, dependiendo del tema, a veces pasa la clase y usted no entendió nada, entonces digamos que casi siempre hay que buscar una estrategia para el tema, el grupo, que sea pertinente y les sirva como para que algo les quede después de la sesión. 
P. ¿Considera que las estrategias pedagógicas y didácticas son importantes para el desarrollo del proceso de enseñanzaaprendizaje o, por el contrario, son una pérdida de tiempo valioso?

R. No, son muy importantes, precisamente porque si yo les dicto a ellos todo el tiempo de manera magistral una clase, a mi modo de ver puede que al finalizar una clase ellos no hayan captado el tema, algunas cosas o muy pocas, o de pronto puede que hayan entendido todo, pero puede que hayan temas en los que me parece que es más importante ir a la práctica, o ir a una actividad específica que me permita reafirmar mis conocimientos, que me permita consultar, mirar, analizar y producir algo.

P. ¿La utilización de las estrategias pedagógicas y didácticas corresponden a una táctica previa a la clase? ¿Por qué?

R. Pues debe ser una estrategia previa, porque yo no puedo improvisar una estrategia pedagógica sobre el camino, digamos que yo tengo que ver el tema, la pertinencia de la estrategia, si se aplica, si es favorable, porque si no, sería muchas veces una pérdida de tiempo.

P. ¿Considera que se ha apropiado de las estrategias pedagógicas y didácticas o solamente les ha dado uso?

R. Yo las he apropiado, porque muchas veces me toca utilizar cosas que encuentro, modificarlas, cambiarlas y utilizarlas para otro tema, o de un tema específico me sirve para otro, entonces es solamente como cambiar la estructura y entonces las reutilizo.

P. ¿El servicio de biblioteca de su institución tiene acceso a bases de datos e información actualizada en la nube, así como videos, libros virtuales y lectores digitales en préstamo, que le permite documentarse sobre estrategias pedagógicas y didácticas?

R. Pues yo sé que la biblioteca cuenta con material muy bueno para algunas de las áreas en las que yo trabajo, pero la verdad nunca me he tomado la molestia de mirar si tiene de estrategias pedagógicas.

P. ¿Se comunica con los estudiantes a través de plataformas virtuales, correos electrónicos, video conferencias u otros recursos digitales? ¿Qué estrategias pedagógicas y didácticas aplica y como las incorpora a través de las herramientas TIc?

R. Todo el tiempo, siempre, utilizo el correo, las aulas virtuales, la videoconferencia, porque a veces por alguna cuestión necesitamos vernos y no podemos en la universidad, entonces utilizamos otras estrategias para no perder la sesión de clase.

P. ¿Qué estrategias pedagógicas y didácticas aplica y cómo las incorpora a través de las herramientas TIC?

R. Pues digamos que en las TIC a nosotros los ingenieros se nos facilita utilizar estrategias pedagógicas, como hacer que el estudiante utilice muchas herramientas multimediales que existen, por ejemplo: para mostrar sus trabajos, para mostrar sus tareas, o utilizamos nosotros mismos herramientas multimediales también para exponer nuestros trabajos, nuestra información, nuestro producto, para que ellos lo vean, lo entiendan, lo analicen, a través de videos, mapas y estructuras.

P. ¿Qué dificultades conoce que han tenido sus estudiantes respecto al uso de las estrategias pedagógicas y didácticas al cumplir con sus actividades académicas?

R. Pues digamos que aquí se tiene bastante problema por el uso del internet, entonces cuando ellos necesitan acceder a herramientas, cuando necesitan utilizar diferentes cosas en la universidad, entonces la red no funciona, no hay servicio, no hay disponibilidad, entonces eso nos hace demorar y no podemos realizar la actividad como la teníamos planeada, esa es la mayor dificultad.

P. ¿Qué dificultades ha encontrado como docente en el uso de las estrategias pedagógicas y didácticas?

R. Pues es que si no tengo servicio de internet a mí se me dificulta subir la actividad, descargar los trabajos de los estudiantes, evaluar, retroalimentar. Además, pues cuando yo entré a la Universidad me sentía perdida porque manejaban el aula virtual y yo no tenía conocimiento, entonces empezar a trabajar eso, digamos que la capacitación la recibí después y ahí yo ya había mirado algo, ya había trabajado algo, pero digamos que, así de entradita, es complicado el manejo del aula.

P. ¿Qué ventajas considera que le proveen las estrategias pedagógicas y didácticas para sus clases?

R. Pues son un soporte, una ayuda, una retroalimentación, me permiten mostrarle al estudiante la información de donde yo puedo consultar, de donde a mí me parece interesante alguna información, algún tema; entonces lo que yo hago es referenciarles esa información al estudiante para que él también pueda analizar, estudiar o conceptualizarse sobre lo mismo que yo estoy leyendo.

P. ¿Cómo cree que se podría fomentar el uso de las estrategias pedagógicas y didácticas en los docentes de su institución universitaria?

R. Pues de pronto a través de capacitaciones para que les sea más fácil utilizarlas, yo he visto que cuando trabajo con profesionales ajenos a mi área se les hace más complicado utilizar alguna estrategia virtual o tecnológica por falta de conocimiento acerca de las mismas, le tienen terror, entonces a los docentes les faltan más capacitaciones de las tecnologías.

Código | US-E-05- -UNIMINUTO Soacha-Entrevista-05- 


\section{APÉNDICE D. MATRIZ DE ANÁLISIS}

\begin{tabular}{|c|c|c|c|c|}
\hline 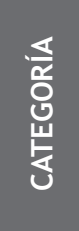 & 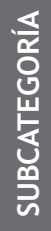 & 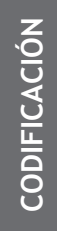 & DESCRIPTOR & $\begin{array}{l}\text { COMENTARIOS - TEXTOS - CITAS } \\
\text { TRIANGULACIÓN POR TIEMPO, ESPACIOS Y PERSONAS }\end{array}$ \\
\hline 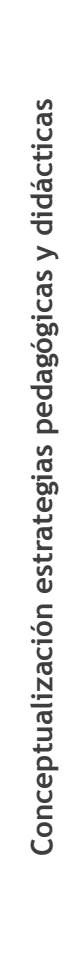 & & 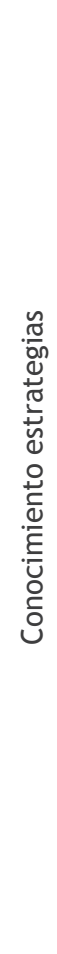 & $\begin{array}{l}\text { Conocen el significado de estra- } \\
\text { tegias pedagógicas y didácticas, } \\
\text { aunque para una pequeña mues- } \\
\text { tra de ellos es confuso expresar- } \\
\text { lo a través de una definición } \\
\text { - Demuestran su conocimiento al } \\
\text { exponer el tipo de estrategias } \\
\text { utilizadas } \\
\text { - El tiempo de conocimiento es } \\
\text { amplio acorde a la formación } \\
\text { académica y experiencia profe- } \\
\text { sional }\end{array}$ & 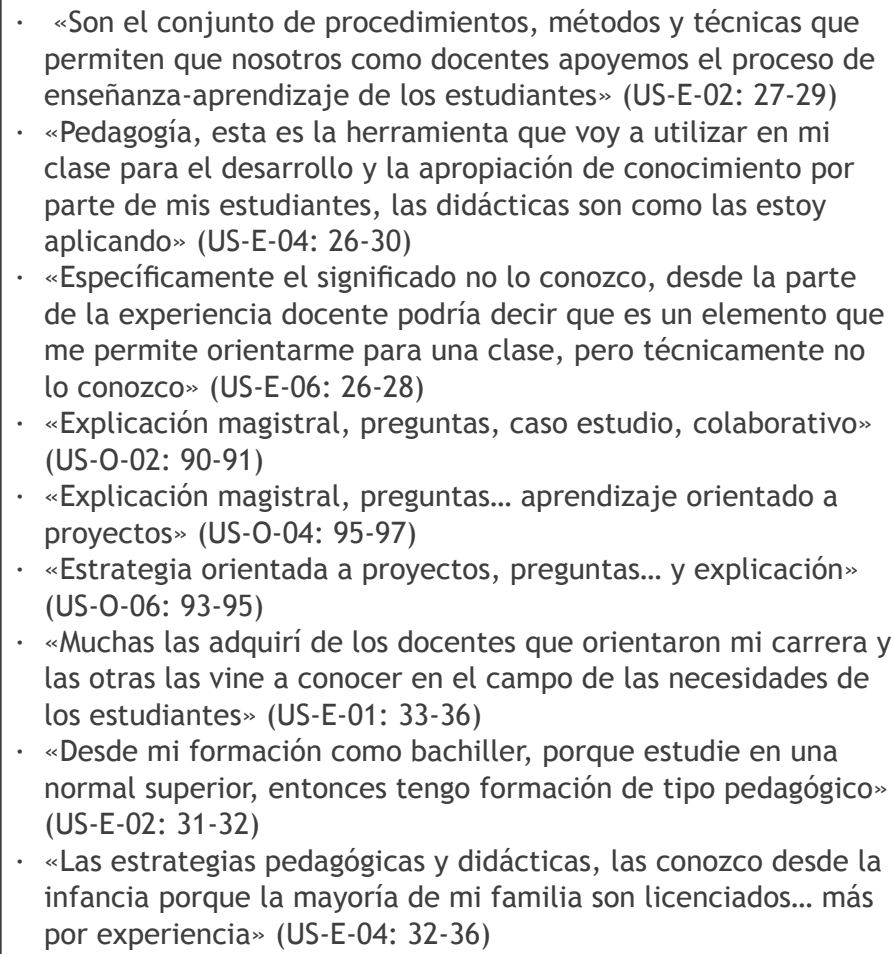 \\
\hline 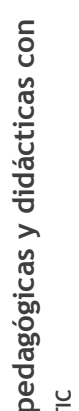 & 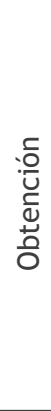 & 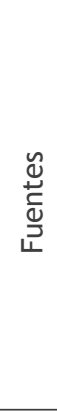 & $\begin{array}{l}\text { Entre las fuentes que relacionan } \\
\text { los docentes para la selección } \\
\text { de las estrategias: experiencia, } \\
\text { conocimiento familiar, internet } \\
\text { y apoyo de los compañeros }\end{array}$ & $\begin{array}{l}\text { - «El conocimiento viene de la parte familiar... el internet, los } \\
\text { libros... el apoyo de algunos compañeros» (US-E-2: } 56-61 \text { ) } \\
\text { - «Pues lo utilizo a partir de mi vivencia personal, de mi expe- } \\
\text { riencia como profesora y como estudiante» (US-E-5: } 51-57 \text { ) } \\
\text { - «Realmente son relacionados a partir de la experiencia... pro- } \\
\text { fundizar en recursos bibliográficos, en internet» (US-E-6: 59-68) } \\
\text { - «Basada en la experiencia normalista, también utiliza recursos } \\
\text { web» (US-O-2: 92-95) } \\
\text { - «A través de la experiencia docente y la web» (US-0-5: 91-92) } \\
\text { - «A través de la experiencia como docente, utiliza y se apoya en } \\
\text { las herramientas web y TIC» (US-0-3: 96-98) }\end{array}$ \\
\hline 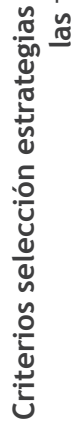 & 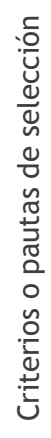 & 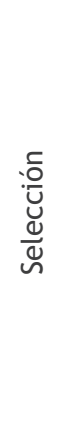 & $\begin{array}{l}\text { Los docentes refieren los } \\
\text { siguientes criterios para la } \\
\text { selección de las estrategias, } \\
\text { aunque algunos de ellos lo re- } \\
\text { presentan a partir de ejemplos: } \\
\text { conocimiento del contenido, } \\
\text { experiencia, validez, comprensi- } \\
\text { vida,variedad, adecuación, rele- } \\
\text { vancia, claridad, conocimiento y } \\
\text { dominio de los procedimientos }\end{array}$ & $\begin{array}{l}\text { - «Lo primero que miro son los contenidos, lo segundo, el grupo } \\
\text { con el que voy a trabajar, y tercero, empiezo a mirar si trabajo } \\
\text { con guías de trabajo o empiezo a generar diferentes estrategias } \\
\text { de juego... relevancia... entorno, experiencia como docente» } \\
\text { (US-E-3: 59-84) } \\
\text { - «Sobre el contenido y contexto de los estudiantes -se analiza } \\
\text { el grupo y el rendimiento-, entonces [se] programa o diseña } \\
\text { las guías de aprendizaje, materiales y otros» (US-0-3: 101-104) } \\
\text { - «Pues los criterios como tales son el grupo al que se le va a } \\
\text { aplicar la estrategia, el tema que se va a tratar en la sesión y } \\
\text { el tiempo de la sesión» (US-E-5: } 60-71 \text { ) } \\
\text {. «Sobre los contenidos» (US-0-5: } 91-92 \text { ) }\end{array}$ \\
\hline
\end{tabular}




\begin{tabular}{|c|c|c|c|c|}
\hline $\begin{array}{l}\frac{\nwarrow}{\alpha 0} \\
\text { 号 } \\
\frac{1}{4}\end{array}$ & 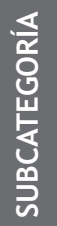 & $\begin{array}{l}z \\
\text { o } \\
\text { ư } \\
\text { un } \\
\overline{0} \\
\text { O }\end{array}$ & DESCRIPTOR & $\begin{array}{c}\text { COMENTARIOS - TEXTOS - CITAS } \\
\text { TRIANGULACIÓN POR TIEMPO, ESPACIOS Y PERSONAS }\end{array}$ \\
\hline \multirow{2}{*}{ 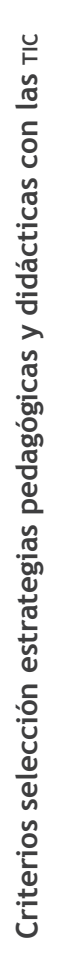 } & 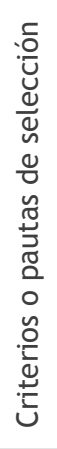 & 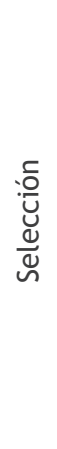 & & $\begin{array}{l}\text { «Contenido a orientar, lo evalúo según lo que posiblemente se } \\
\text { podría orientar [...] la estrategia que uno planea no coincide } \\
\text { con el grupo, entonces es necesario orientar o adaptar el grupo } \\
\text { en otra estrategia [...] desarrollo de estrategias que apunten al } \\
\text { objetivo que tiene cada corte: si en cada corte yo tengo que } \\
\text { desarrollar una fase de los elementos que están planteados } \\
\text { en el contenido, mido el tiempo, hago la división y por fases } \\
\text { y talleres, verifico que se cumpla el final de ese objetivo [...] } \\
\text { adecuar lo que es relevante, darle prioridades» (US-E-6: 71-91) } \\
\text {. «De acuerdo a las necesidades del contenido y de los estudian- } \\
\text { tes, basada en la experiencia y recursos de internet» (US-0-6: } \\
\text { 96-99) }\end{array}$ \\
\hline & 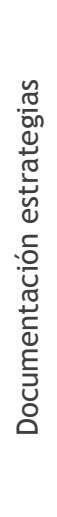 & 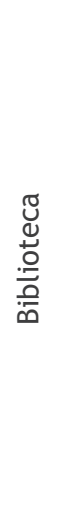 & $\begin{array}{l}\text { Los docentes refieren que la } \\
\text { biblioteca de la universidad } \\
\text { cuenta con recursos físicos y } \\
\text { virtuales, pero no han profun- } \\
\text { dizado sobre documentación } \\
\text { de estrategias pedagógicas y } \\
\text { didácticas }\end{array}$ & $\begin{array}{l}\text { «La universidad cuenta con libros físicos como bases de datos. } \\
\text { Los físicos con los que yo estoy dictando actualmente están } \\
\text { obsoletos. No he averiguado si en la biblioteca hay documen- } \\
\text { tación sobre estrategias pedagógicas y didácticas» (US-E-1: } \\
\text { 113-115) } \\
\text { - «Sí, definitivamente la Corporación Universitaria Minuto de } \\
\text { Dios tiene una muy buena biblioteca, no solamente física sino } \\
\text { virtual, la verdad yo utilizo todo el tiempo la virtual, no sola- } \\
\text { mente sobre estrategias sino sobre los conocimientos propios } \\
\text { de la carrera que están trabajando los estudiantes» (US-O-2: } \\
111-114 \text { ) } \\
\text { «En cuanto a estrategias pedagógicas y didácticas no he mira- } \\
\text { do, en cuanto a mi carrera sí, pero en cuanto a estrategias no } \\
\text { tengo ni idea» (US-E-3: 124-125) }\end{array}$ \\
\hline \multirow{2}{*}{ 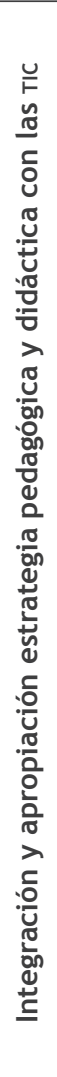 } & 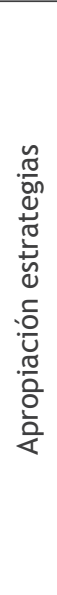 & $\begin{array}{l}: \frac{.}{c} \\
\frac{\bar{c}}{0} \\
\end{array}$ & $\begin{array}{l}\text { - Los docentes han apropiado las } \\
\text { estrategias } \\
\text { Cipantes exponen lo difícil que } \\
\text { representa apropiar, por lo que } \\
\text { señalan su integración }\end{array}$ & $\begin{array}{l}\text { - «a docente utiliza y se ha apropiado de las estrategias didácti- } \\
\text { cas y pedagógicas» (US-O-03: 39-40) } \\
\text {. «La docente utiliza algunas estrategias integrando las TIC» (US- } \\
\text { O-05: 34-35) } \\
\text {. «La docente apropia estrategias didácticas y pedagógicas, se } \\
\text { apoya integrando las TIC» (US-0-06: 36) } \\
\text {. «Totalmente, me he hecho dueña de estas estrategias, porque } \\
\text { tengo claro cuál es mi función y cada día estoy buscando el } \\
\text { mejoramiento de la educación» (US-E-02: 102-106) } \\
\text {. «Apropiarlas es complejo... digamos que yo traté de darle un } \\
\text { toque al contexto, traté de medianamente adaptarla al contex- } \\
\text { to, pero hacer una apropiación, no, pienso que a nivel ingenie- } \\
\text { ril es muy complejo» (US-E-04: 109-122) } \\
\text { - «Yo las he apropiado, porque muchas veces me toca utilizar } \\
\text { cosas que encuentro, modificarlas, cambiarlas y utilizarlas» } \\
\text { (US-E-05: 98-101) }\end{array}$ \\
\hline & 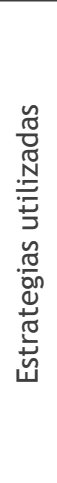 & ○̆ & $\begin{array}{l}\text { Los docentes utilizan siempre } \\
\text { las estrategias, aunque algu- } \\
\text { nos no conocen que las estén } \\
\text { ejecutando } \\
\text { - La frecuencia de uso de las } \\
\text { estrategias es alta, en gene- } \\
\text { ral, aproximada al semestre } \\
\text { académico } \\
\text { - Estrategias utilizadas: } \\
\text { - Instrucción magistral } \\
\text { - Argumentación } \\
\text { - Exposiciones } \\
\text { - Trabajo colaborativo }\end{array}$ & $\begin{array}{l}\text { «Sí, con herramientas trato de hacer lo que más se pueda fren- } \\
\text { te a las materias que estoy manejando actualmente» (US-E-1: } \\
\text { 39-40) } \\
\text {. «Todo el tiempo [...] es importante para ellos que el aprendiza- } \\
\text { je sea significativo» (US-E-2: } 35-38) \\
\text {. «Teóricamente no sé qué estrategia he utilizado, pero conside- } \\
\text { ro que partiendo de la parte teórica que pueda representar, he } \\
\text { tratado de implementarlas en lo que he desarrollado» (US-E-6: } \\
\text { 35-37) } \\
\text {. «Siempre... pues, como te decía anteriormente, es importante } \\
\text { que nosotros las utilicemos a diario en nuestra labor» (US-E-2: } \\
80-84 \text { ) }\end{array}$ \\
\hline
\end{tabular}




\begin{tabular}{|c|c|c|c|c|}
\hline & 岁 & & DESCRIPTOR & $\begin{array}{c}\text { COMENTARIOS - TEXTOS - CITAS } \\
\text { TRIANGULACIÓN POR TIEMPO, ESPACIOS Y PERSONAS }\end{array}$ \\
\hline \multirow{3}{*}{ 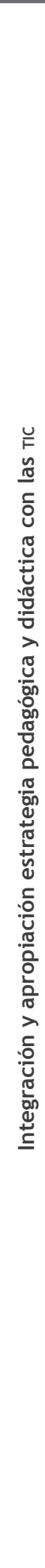 } & 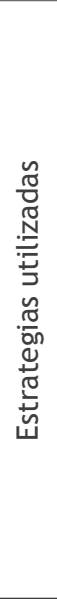 & 乌̆ & $\begin{array}{l}\text { - Evaluación Aprendizaje por } \\
\text { investigación }\end{array}$ & 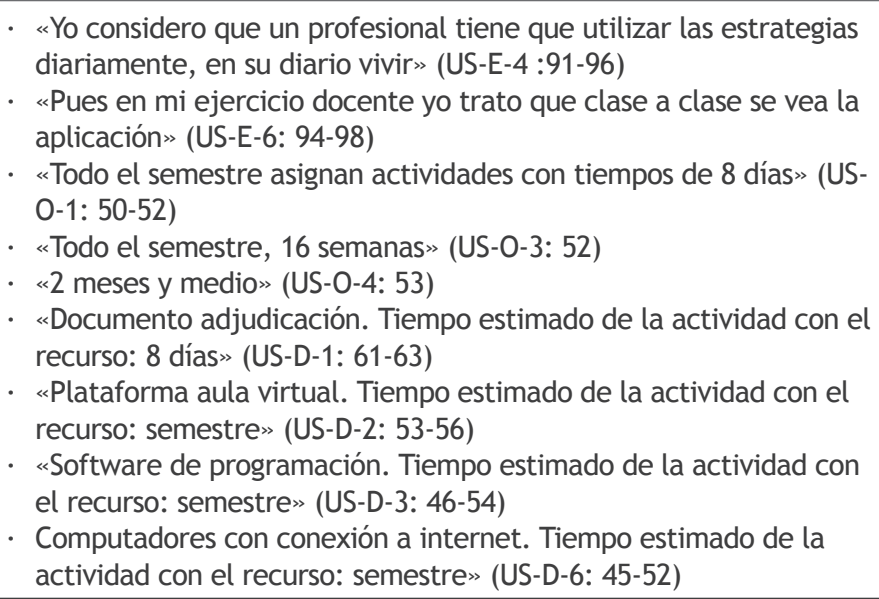 \\
\hline & 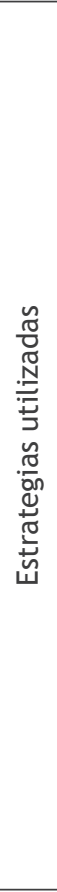 & $\stackrel{\circ}{\Omega}$ & $\begin{array}{l}\text { Talleres } \\
\text { Juegos } \\
\text { - Aprendizaje orientado a pro- } \\
\text { yectos } \\
\text { - Preguntas abiertas y cerradas } \\
\text { Autoaprendizaje } \\
\text { - Explicación instruccional Plata- } \\
\text { formas virtuales como medios } \\
\text { de interacción: aulas, progra- } \\
\text { mas, otros } \\
\text { - Cuadros comparativos } \\
\text { - Estudio de casos }\end{array}$ & 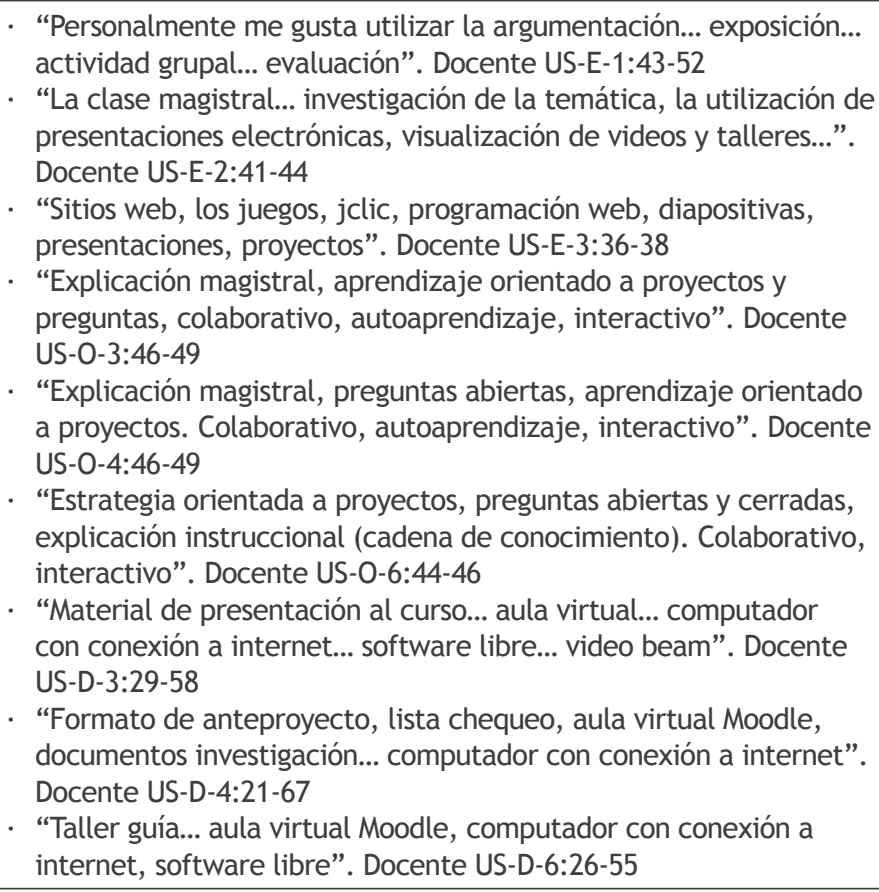 \\
\hline & 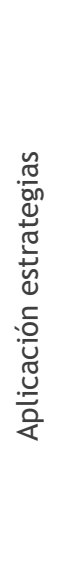 & 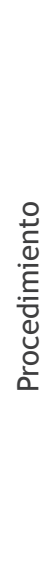 & $\begin{array}{l}\text { - Las estrategias y/o actividades } \\
\text { de clase son programadas te- } \\
\text { niendo en cuenta los siguientes } \\
\text { parámetros, aunque la estruc- } \\
\text { tura puede variar: Nombre } \\
\text { actividad } \\
\text { - Tipo estrategia } \\
\text { - Clasificación estrategia } \\
\text { - Alcance } \\
\text { - Objetivos }\end{array}$ & $\begin{array}{l}\text { "La profesora indica instrucciones para ingresar al aula virtual, } \\
\text { descargar unos archivos y aplicar observaciones al proyecto, con la } \\
\text { lista de chequeo evalúa y retroalimenta.". Docente US-O-4:20-22 } \\
\text { "Comprensión del contenido, aplicación al contexto. Utiliza casos } \\
\text { de la vida convencional, enfoca el aprendizaje hacia el desarrollo } \\
\text { de proyectos interdisciplinares, retroalimenta el conocimiento". } \\
\text { Docente US-0-4:105-110 } \\
\text {. "Nombre: proyecto investigación, Tipo estrategia: explicación } \\
\text { magistral, preguntas abiertas, aprendizaje orientado a proyectos, } \\
\text { Clasificación estrategia: colaborativo, autoaprendizaje, interac- } \\
\text { tivo, Alcance: } 2 \text { meses y medio, Objetivos: Construción de un } \\
\text { proyecto de investigación..., Contenido: metodología investigación, } \\
\text { Secuencia didáctica: la profesora indica instrucciones sobre el } \\
\text { ingreso al aula virtual y descarga..., Recursos y medios: computa- } \\
\text { dores e internet, Estrategias de evaluación: nota porcentual de la } \\
\text { nota final del proyecto". Docente US-0-4:43-73 }\end{array}$ \\
\hline
\end{tabular}




\begin{tabular}{|c|c|c|c|c|}
\hline $\begin{array}{l}\frac{\nwarrow}{\alpha} \\
\text { 号 } \\
\frac{\mathrm{E}}{\mathrm{c}}\end{array}$ & 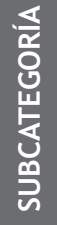 & 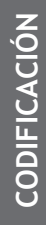 & DESCRIPTOR & $\begin{array}{l}\text { COMENTARIOS - TEXTOS - CITAS } \\
\text { TRIANGULACIÓN POR TIEMPO, ESPACIOS Y PERSONAS }\end{array}$ \\
\hline 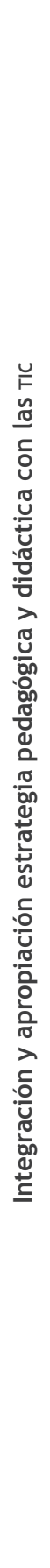 & 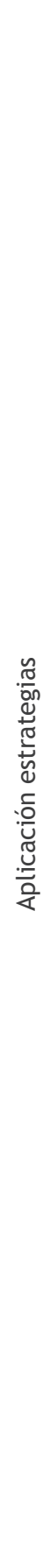 & 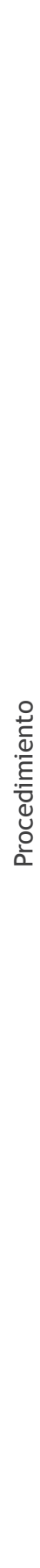 & $\begin{array}{l}\text { Contenido: planeación del par- } \\
\text { celador (actividades vs conteni- } \\
\text { do vs tiempo) } \\
\text { - Se apoyan en material bibliográ- } \\
\text { fico, infografía o material propio } \\
\text { - Secuencia didáctica. } \\
\text { - Retroalimentan la actividad } \\
\text { - Recursos y medios: utilizan com- } \\
\text { putadores, internet, programas, } \\
\text { aula virtual, video beam } \\
\text { - Estrategias de evaluación } \\
\text { - En la aplicación de estrategias } \\
\text { pedagógicas y didácticas, los } \\
\text { docentes incorporan las TIC, con } \\
\text { recursos y medios como compu- } \\
\text { tadores, equipos proyectores, } \\
\text { aula virtual, software interacti- } \\
\text { vo, correo, redes sociales, entre } \\
\text { otros }\end{array}$ & 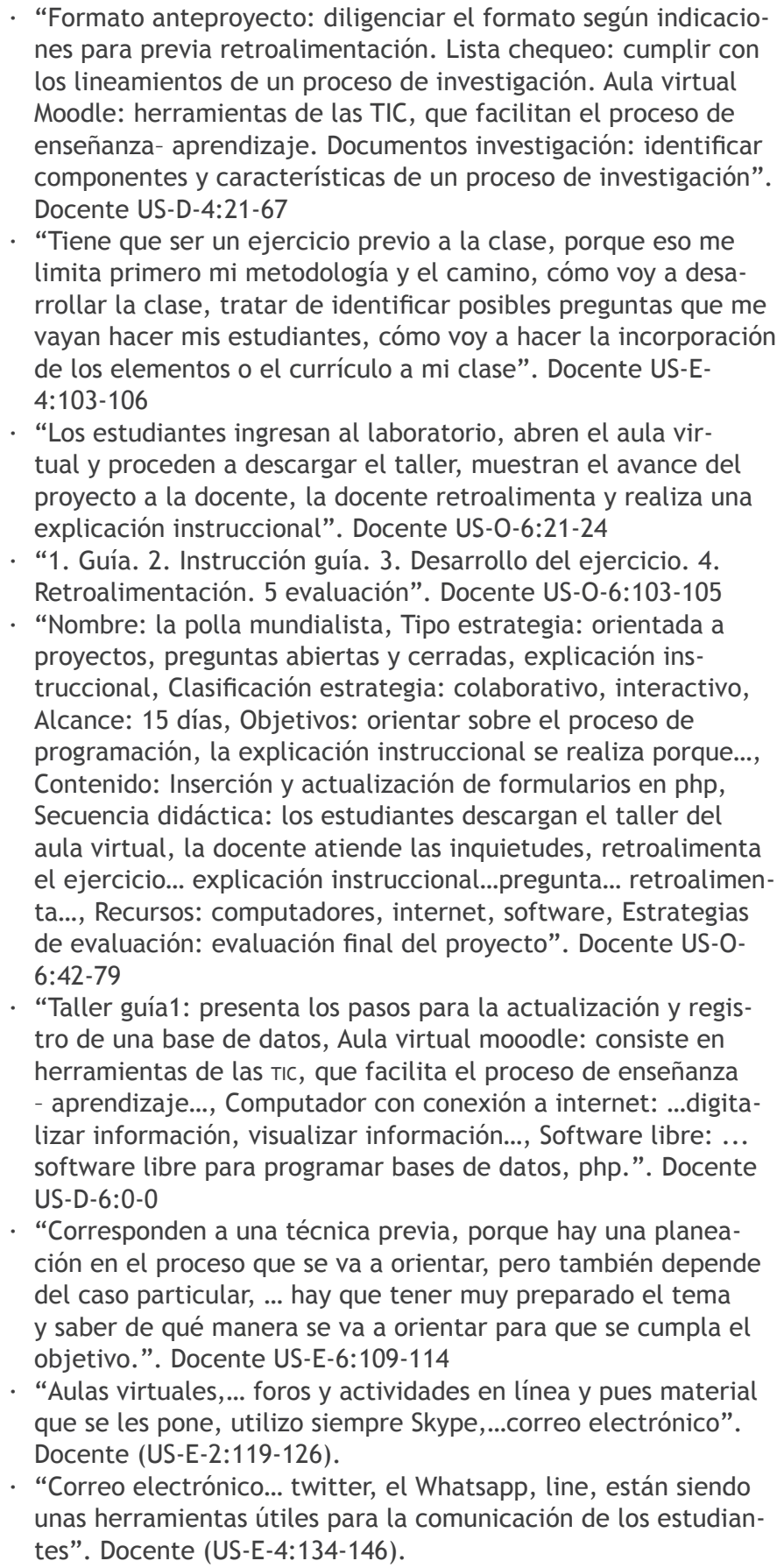 \\
\hline
\end{tabular}




\begin{tabular}{|c|c|c|c|c|}
\hline & 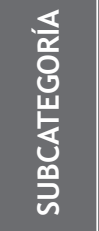 & 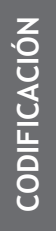 & DESCRIPTOR & $\begin{array}{c}\text { COMENTARIOS - TEXTOS - CITAS } \\
\text { TRIANGULACIÓN POR TIEMPO, ESPACIOS Y PERSONAS }\end{array}$ \\
\hline \multirow{4}{*}{ 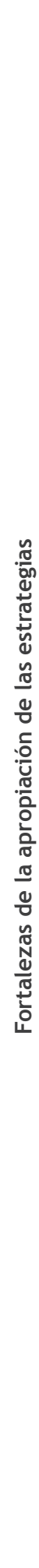 } & \multirow{2}{*}{ 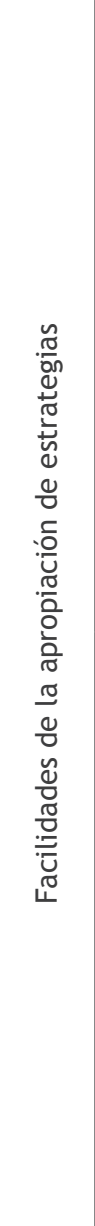 } & 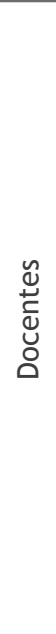 & $\begin{array}{l}\text { Los docentes atañen la facilidad } \\
\text { en la incorporación de las TIC } \\
\text { en las estrategias pedagógicas y } \\
\text { didácticas, basados en su forma- } \\
\text { ción y experiencia en el área }\end{array}$ & $\begin{array}{l}\text { - “Obtener las estrategias es fácil, pero requiere tiempo para el } \\
\text { correcto desarrollo.... facilidad en la utilización de las estrate- } \\
\text { gias apoyado en las TIC, por la formación y gestión eficiente de } \\
\text { las TIC". Docente US-0-6:107-118 } \\
\text {. “Facilidad en la obtención, selección e integración de las TIC, } \\
\text { por conocimientos previos, experiencia a fin al área, a través } \\
\text { de la Web”. Docente US-O-4:110-121 } \\
\text {. "Facilidad en la obtención, selección e integración de las TIC, } \\
\text { por experiencia docente y el conocimiento de las herramientas } \\
\text { Web...depende también del grupo... entra el análisis del conte- } \\
\text { nido, contexto y población”. Docente US-O-3:110-122 } \\
\text {. “Facilidad en la obtención, selección e integración de las TIC, } \\
\text { por el grupo y contexto,.... por conocimiento sobre las TIC, por la } \\
\text { formación y experiencia.”. Docente US-0-5:101-105 } \\
\text {. "Facilidad en la obtención, selección e integración de las TIC, } \\
\text { por conocimiento previo y experiencia normalista, a través de } \\
\text { la Web". Docente US-0-2:101-112 }\end{array}$ \\
\hline & & 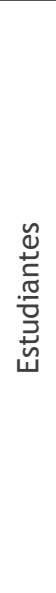 & $\begin{array}{l}\text { Los docentes reseñan que la in- } \\
\text { teracción de los estudiantes con } \\
\text { las estrategias es fácil, por las } \\
\text { diferentes y variadas estrategias } \\
\text { y didácticas incluidas en clase }\end{array}$ & $\begin{array}{l}\text { - “La interacción de los estudiantes frente a las estrategias es } \\
\text { fácil; las Est. Son de agrado para los estudiantes, la profesora } \\
\text { los retroalimenta y verifica que hayan avances en sus aprendi- } \\
\text { zajes". Docente US-0-6:80-91 } \\
\text {. “La interacción de los estudiantes frente a las estrategias es } \\
\text { fácil; interactúan con la clase, lectura del material del aula } \\
\text { virtual, facilidad del ejercicio programado... facilita el aprendi- } \\
\text { zaje para los estudiantes, con ejercicios prácticos aterrizados a } \\
\text { las necesidades de la actualidad". Docente US-0-3:82-91 } \\
\text { "La interacción de los estudiantes frente a las estrategias es } \\
\text { fácil; la teoría es apoyada con ejemplos reales". Docente US- } \\
\text { O-5:77-82 } \\
\text { "La interacción de los estudiantes frente a las estrategias es } \\
\text { fácil;;...lectura del material del aula virtual, facilidad del ejer- } \\
\text { cicio programado...con esta metodología facilita el aprendizaje } \\
\text { para los estudiantes". Docente US-0-2:77-86 }\end{array}$ \\
\hline & 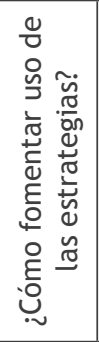 & 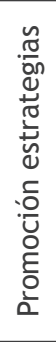 & $\begin{array}{l}\text { Sensibilización sobre los benefi- } \\
\text { cios de las estrategias pedagógi- } \\
\text { cas y didácticas en los espacios } \\
\text { académicos } \\
\text { Capacitación para los docentes } \\
\text { sobre la incorporación }\end{array}$ & $\begin{array}{l}\text { "UNIMINUTO destine y tenga en cuenta que todos los docen- } \\
\text { tes.... Requiere que se les capacite, se les instruya en ese } \\
\text { proceso de estrategias pedagógicas y didácticas". Docente } \\
\text { US-E-6:171-178 } \\
\text {.Que nos capaciten por campos de conocimiento y en esos } \\
\text { campos de conocimiento identificar experiencias exitosas, tan- } \\
\text { to de otros autores, como de nuestros compañeros de trabajo } \\
\text { en la aplicación de contenidos y temáticas de clase”. Docente } \\
\text { US-E-4:173-179 }\end{array}$ \\
\hline & 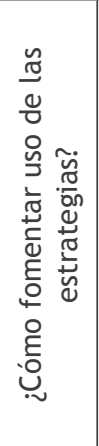 & 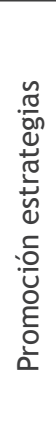 & $\begin{array}{l}\text { De estrategias pedagógicas } \\
\text { y didácticas en los procesos } \\
\text { de enseñanza - aprendizaje, } \\
\text { mediados por las TIC, identifi- } \\
\text { cando casos exitosos para ser } \\
\text { compartidos en la comunidad } \\
\text { académica }\end{array}$ & $\begin{array}{l}\text {-Yo creo que una capacitación y mostrar cómo se utilizan las } \\
\text { diferentes aulas didácticas que hay en internet o recursos que } \\
\text { hay y una persona que fuera muy especializada y nos mostrara } \\
\text { los diferentes eventos que hay, cómo se utilizan". Docente (US- } \\
\text { E-3:178-186) } \\
\text {. "Pues de pronto a través de capacitaciones, para que les sea } \\
\text { más fácil utilizarlas,... entonces a los docentes les falta más } \\
\text { capacitaciones de la tecnologías". Docente (US-E-5:149-153) } \\
\text { "Pues yo creo que eso es un proceso autoreflexivo, yo creo que } \\
\text { en el momento en el que el docente reconoce la importancia } \\
\text { de su labor se apropia de ellas... buscando conocimiento para } \\
\text { los estudiantes significativos". Docente (US-E-2:149-156) }\end{array}$ \\
\hline
\end{tabular}




\begin{tabular}{|c|c|c|c|c|}
\hline $\begin{array}{l}\frac{\nwarrow}{\alpha} \\
\text { 号 } \\
\frac{1}{\mathbf{c}}\end{array}$ & 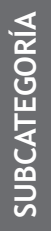 & $\begin{array}{l}z \\
\text { zo } \\
\text { 언 } \\
\text { 응 }\end{array}$ & DESCRIPTOR & $\begin{array}{l}\text { COMENTARIOS - TEXTOS - CITAS } \\
\text { TRIANGULACIÓN POR TIEMPO, ESPACIOS Y PERSONAS }\end{array}$ \\
\hline 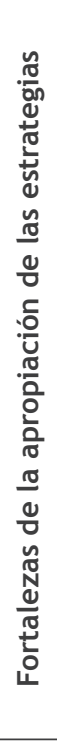 & 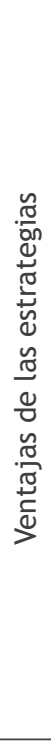 & 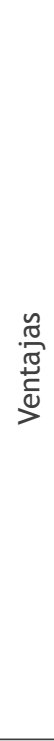 & $\begin{array}{l}\text { - Las estrategias P. y D. son atrac- } \\
\text { tivas para los estudiantes, por lo } \\
\text { que capturan su atención y los } \\
\text { involucra en la construcción del } \\
\text { aprendizaje } \\
\text { - Las TIC como herramienta media- } \\
\text { dora eficiente, incentivan a los } \\
\text { estudiantes en su formación } \\
\text { - La virtualidad genera espacios } \\
\text { de autoaprendizaje }\end{array}$ & $\begin{array}{l}\text { “El tema y explicación captura la atención de los estudiantes y } \\
\text { los involucra". Docente US-0-6:27-31; docente US-0-3:30-34; } \\
\text { docente US-0-2:26-30 } \\
\text {. “Una buena estrategia puedo lograr que mis estudiantes tengan } \\
\text { esa aprensión... el resultado es bueno". Docente US-E-6:164- } \\
168 \\
\text {. “La apropiación del conocimiento por parte del estudiante, } \\
\text { yo pienso que si no hay apropiación del conocimiento, no hay } \\
\text { enseñanza”. Docente US-E-4:169-170 } \\
\text {. “Muchas, si yo no utilizo las estrategias didácticas o lo que yo } \\
\text { manejo online, los estudiantes no aprenderían tan rápido y } \\
\text { no me darían lo que yo quiero evaluar en tan corto tiempo". } \\
\text { Docente US-E-3:167-175 } \\
\text {. “Pues son un soporte, una ayuda, una retroalimentación”. } \\
\text { Docente US-E-5:142-146 } \\
\text { "El aprovechamiento del tiempo no solamente se valora la } \\
\text { presencialidad, sino también el uso de herramientas tecno- } \\
\text { lógicas como las aulas virtuales o como el hecho de que ellos } \\
\text { puedan consultar a través de internet la biblioteca”. Docente } \\
\text { US-E-2:143-146 }\end{array}$ \\
\hline \multirow[t]{2}{*}{ 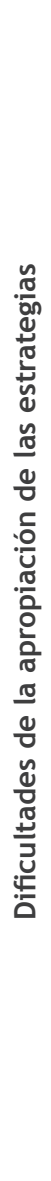 } & \multirow[t]{2}{*}{ 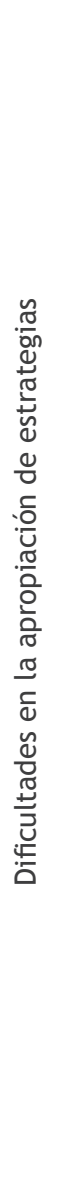 } & 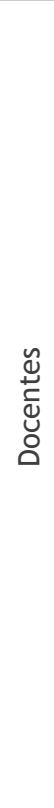 & $\begin{array}{l}\text { - La mayor dificultad es el pro- } \\
\text { blema de conexión a internet; } \\
\text { a esto se suma que todos los } \\
\text { docentes utilizan el aula virtual, } \\
\text { lo que obstaculiza el correcto } \\
\text { desarrollo de las clases } \\
\text { - Los docentes no cuentan con } \\
\text { el software requerido para las } \\
\text { clases } \\
\text { - El tiempo de preparación de las } \\
\text { clases es insuficiente } \\
\text { Desconocimiento de las diferen- } \\
\text { tes estrategias y cómo selec- } \\
\text { cionarlas de acuerdo al tema y } \\
\text { contexto }\end{array}$ & 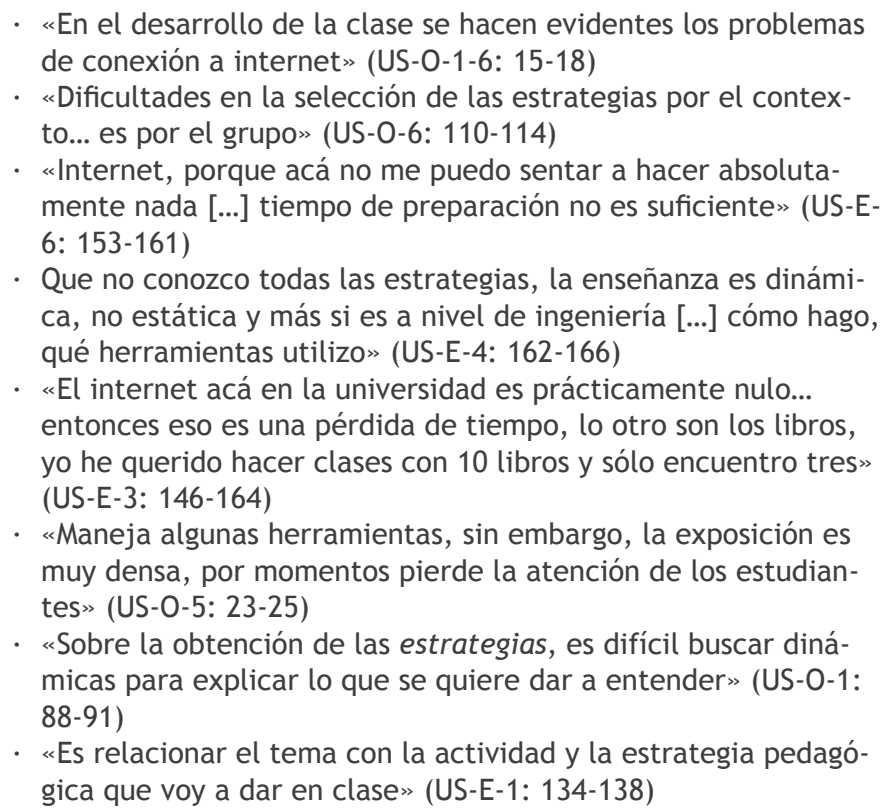 \\
\hline & & 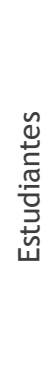 & $\begin{array}{l}\text { La mayor dificultad es el proble- } \\
\text { ma de conexión a internet y a } \\
\text { esto se suma que todos los estu- } \\
\text { diantes utilizan el aula virtual }\end{array}$ & $\begin{array}{l}\text { «Laboratorios, el manejo de internet es un poco complicado } \\
\text { [...] no he contado con el servicio de software [...] el recurso } \\
\text { físico y la red han sido la dificultad» (US-E-6: 143-150) } \\
\text {. «Dificultad de la interacción con las estrategias; por parte de } \\
\text { los estudiantes, no por la estrategia, sino por el contenido... la } \\
\text { temática implica que los estudiantes piensen y argumenten» } \\
\text { (US-0-4: } 81-92 \text { ) } \\
\text { - «La conexión es lenta» (US-E-4: 149-159) } \\
\text { - «Para los estudiantes es difícil esquematizar o realizar cuadros } \\
\text { comparativos» (US-0-5: } 83-86 \text { ) }\end{array}$ \\
\hline
\end{tabular}




\begin{tabular}{|c|c|c|c|c|}
\hline 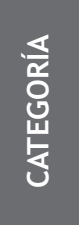 & 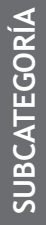 & $\begin{array}{l}z \\
\text { 은 } \\
\frac{u}{1} \\
\overline{0} \\
\text { O }\end{array}$ & DESCRIPTOR & $\begin{array}{l}\text { COMENTARIOS - TEXTOS - CITAS } \\
\text { TRIANGULACIÓN POR TIEMPO, ESPACIOS Y PERSONAS }\end{array}$ \\
\hline 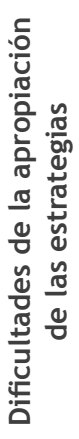 & & 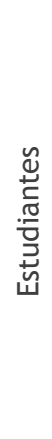 & $\begin{array}{l}\text { - Dificultades por el contenido y } \\
\text { temáticas } \\
\text { - No tienen los medios idóneos } \\
\text { para el trabajo } \\
\text { - Grado de autonomía de los } \\
\text { estudiantes. } \\
\text {. Estrategia vs contexto o grupo }\end{array}$ & $\begin{array}{l}\text { «Por conflictos con algunos grupos y, por lo tanto, hay que } \\
\text { adecuar las estrategias» (US-O-5: 107-109) } \\
\text { - «Por el uso de internet, entonces, cuando ellos necesitan } \\
\text { acceder a herramientas... entonces la red no funciona, no hay } \\
\text { servicio, no hay disponibilidad, entonces eso nos hace demorar } \\
\text { y no podemos realizar la actividad como la teníamos planeada, } \\
\text { esa es la mayor dificultad» (US-E-5: 126-130) } \\
\text { - «Pues en realidad yo creo que es una limitación propia del } \\
\text { estudiante y es la pereza, no frente al conocimiento de las } \\
\text { didácticas ni de las TIC, sino la pereza que tiene el estudiante» } \\
\text { (US-E-2: } 129-136) \\
\text { - «El desarrollo autónomo» (US-E-1: } 125-131 \text { ) }\end{array}$ \\
\hline
\end{tabular}

\section{APÉNDICE E. CUADRO DE TRIPLE ENTRADA}

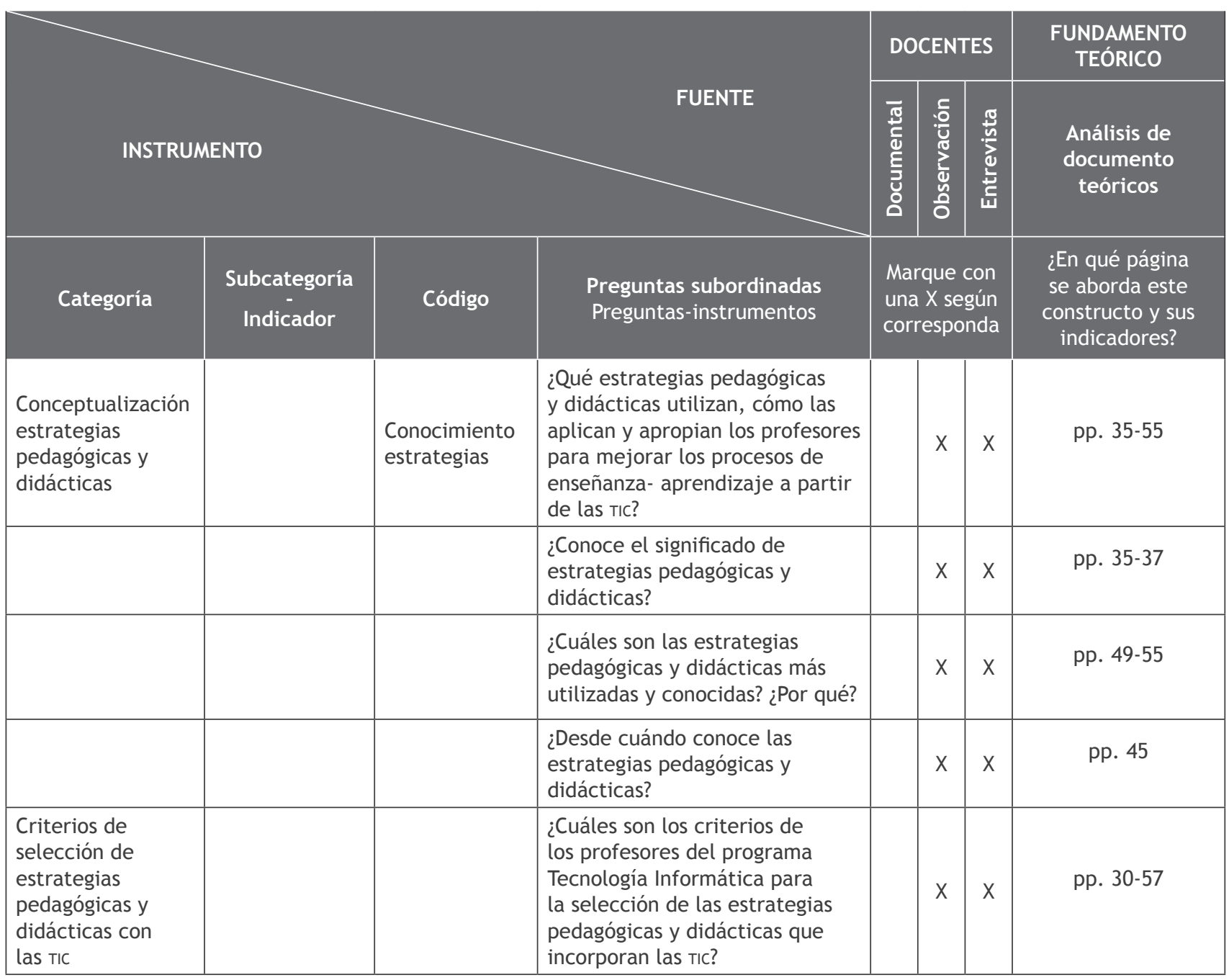




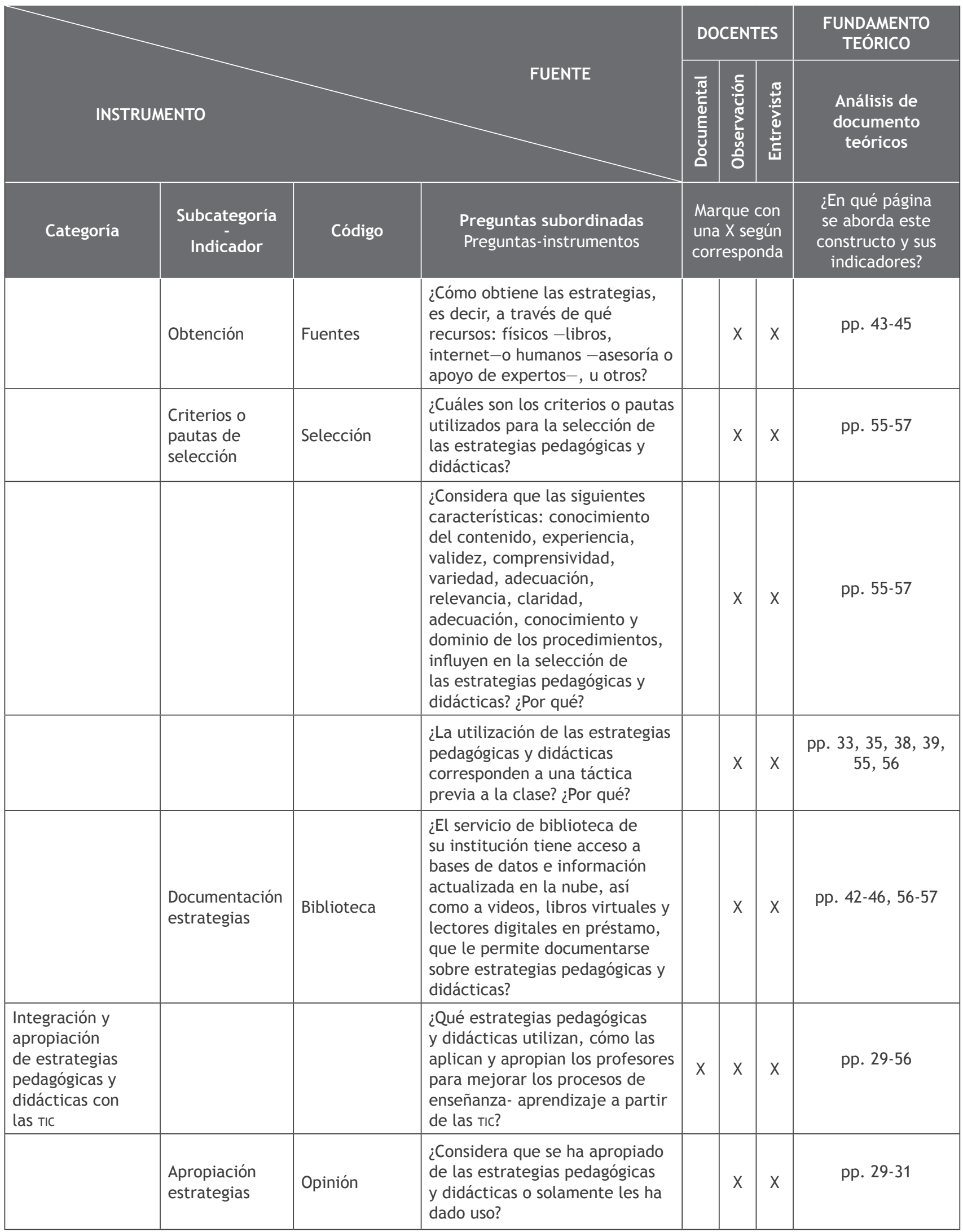




\begin{tabular}{|c|c|c|c|c|c|c|c|}
\hline \multirow{2}{*}{\multicolumn{4}{|c|}{ INSTRUMENTO }} & \multicolumn{3}{|c|}{ DOCENTES } & \multirow{3}{*}{$\begin{array}{c}\begin{array}{c}\text { FUNDAMENTO } \\
\text { TEÓRICO }\end{array} \\
\begin{array}{c}\text { Análisis de } \\
\text { documento } \\
\text { teóricos }\end{array} \\
\begin{array}{c}\text { ¿En qué página } \\
\text { se aborda este } \\
\text { constructo y sus } \\
\text { indicadores? }\end{array}\end{array}$} \\
\hline & & & & 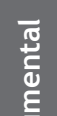 & $\stackrel{\text { :õ }}{:}$ & 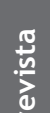 & \\
\hline \multirow[t]{2}{*}{ Categoría } & $\begin{array}{l}\text { Subcategoría } \\
\text { Indicador }\end{array}$ & Código & $\begin{array}{l}\text { Preguntas subordinadas } \\
\text { Preguntas-instrumentos }\end{array}$ & \multicolumn{3}{|c|}{$\begin{array}{l}\text { Marque con } \\
\text { una X según } \\
\text { corresponda }\end{array}$} & \\
\hline & $\begin{array}{l}\text { Estrategias } \\
\text { utilizadas }\end{array}$ & Uso & $\begin{array}{l}\text { ¿Ha utilizado las estrategias } \\
\text { pedagógicas y didácticas en } \\
\text { los procesos de enseñanza- } \\
\text { aprendizaje? }\end{array}$ & $x$ & $x$ & $x$ & pp. 34- 55 \\
\hline & & & $\begin{array}{l}\text { ¿Con qué frecuencia utiliza } \\
\text { las estrategias pedagógicas } \\
\text { y didácticas: siempre, casi } \\
\text { siempre, de vez en cuando? ¿Por } \\
\text { qué? }\end{array}$ & $x$ & $x$ & $x$ & p. 45 \\
\hline & & & $\begin{array}{l}\text { ¿Cuáles son las estrategias } \\
\text { pedagógicas y didácticas más } \\
\text { utilizadas y conocidas? ¿Por qué? }\end{array}$ & $x$ & $x$ & $x$ & pp. 49-55 \\
\hline & $\begin{array}{l}\text { Aplicación de } \\
\text { estrategias }\end{array}$ & Procedimiento & $\begin{array}{l}\text { Las estrategias o actividades de } \\
\text { clase son programadas teniendo } \\
\text { en cuenta parámetros, aunque } \\
\text { la estructura puede variar }\end{array}$ & $x$ & $x$ & $x$ & pp. $47-49,56$ \\
\hline & & & $\begin{array}{l}\text { ¿Cómo apoya e integra las } \\
\text { estrategias pedagógicas y } \\
\text { didácticas con las herramientas } \\
\text { afines a las Tecnologías de la } \\
\text { Información y Comunicación } \\
\text {-TIC-? }\end{array}$ & $x$ & $x$ & $x$ & pp. 43-56 \\
\hline & & & $\begin{array}{l}\text { ¿Se comunica con los } \\
\text { estudiantes a través de } \\
\text { plataformas virtuales, correos } \\
\text { electrónicos, videoconferencias } \\
\text { u otros recursos digitales? } \\
\text { ¿Qué estrategias pedagógicas } \\
\text { y didácticas aplica y cómo } \\
\text { las incorpora a través de las } \\
\text { herramientas tic? }\end{array}$ & $x$ & $x$ & $x$ & pp. $45-47,54$ \\
\hline \multirow[t]{2}{*}{$\begin{array}{l}\text { Fortalezas de la } \\
\text { apropiación }\end{array}$} & & & $\begin{array}{l}\text { ¿Cuáles son las fortalezas y } \\
\text { dificultades que se presentan } \\
\text { al apropiar las estrategias } \\
\text { pedagógicas y didácticas que } \\
\text { incorporan las tic en los procesos } \\
\text { de enseñanza- aprendizaje } \\
\text { del programa Tecnología } \\
\text { Informática? }\end{array}$ & & $x$ & $x$ & pp. $46-58$ \\
\hline & $\begin{array}{l}\text { Facilidades de } \\
\text { la apropiación } \\
\text { de estrategias }\end{array}$ & Docentes & $\begin{array}{l}\text { Facilidad en la incorporación } \\
\text { de las tIc en las estrategias } \\
\text { pedagógicas y didácticas, } \\
\text { basados en su formación y } \\
\text { experiencia en el área }\end{array}$ & & $x$ & $x$ & pp. 32, 45- 47 \\
\hline
\end{tabular}




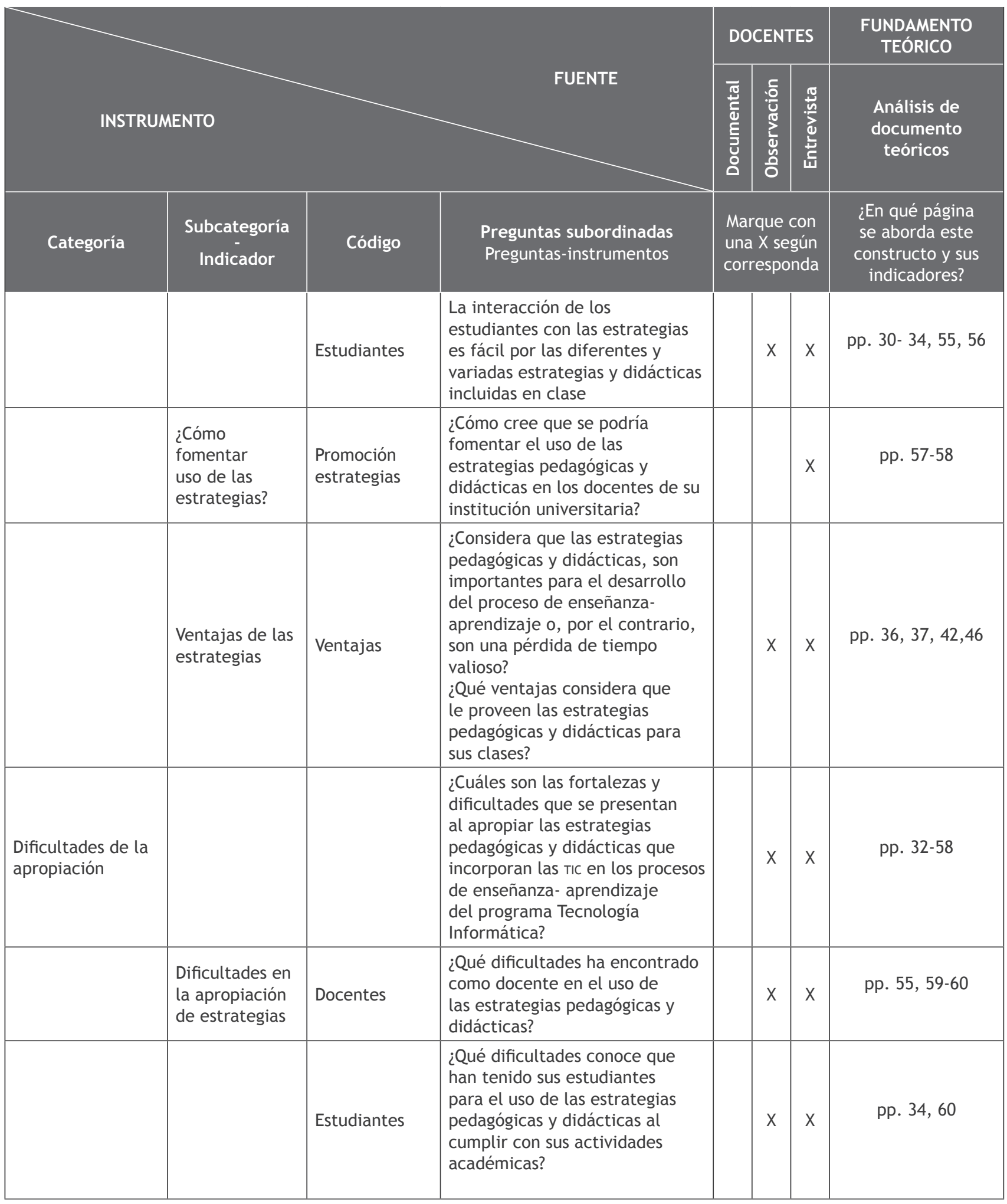

